Wirtschaftswissenschaftliche

Fakultät

\title{
Environmental Policy and Heterogeneous Labor Market Effects: Evidence from Europe
}




\title{
Environmental Policy and Heterogeneous Labor Market Effects: Evidence from Europe
}

\author{
Matthias Niggli*1 and Christian Rutzer ${ }^{2}$ \\ ${ }^{1}$ University of Basel, Switzerland \\ matthias.niggli@unibas.ch \\ ${ }^{2}$ University of Basel, Switzerland \\ christian.rutzer@unibas.ch
}

October 2020

\begin{abstract}
In this paper, we use a data-driven approach to predict the "green potential" of ISCO occupations based on their corresponding skills. With this information, we can investigate the relationship between environmental regulations and occupation-level employment in the manufacturing sector of 19 European countries for the period 1992-2010. Our empirical results highlight heterogeneous occupational employment changes in response to an increase in environmental policy stringency. More specifically, we find a decrease in labor demand for occupations with relatively low green potential and an increase for occupations with relatively high green potential. Thus, at least in the short term, greening the economy may create winners and losers across occupations and countries.
\end{abstract}

Keywords: environmental regulation, green transition, labor market, supervised learning JEL codes: J23, J24, Q52

\footnotetext{
${ }^{*}$ Correspondence address: Matthias Niggli, Faculty of Business and Economics, University of Basel, Peter MerianWeg 6, CH-4002 Basel, Switzerland, email: matthias.niggli@unibas.ch. This work has been supported by the Swiss National Science Foundation (SNSF) within the framework of the National Research Program "Sustainable Economy: resource-friendly, future-oriented, innovative" (NRP 73) Grant-No 407340-172430. The authors declare that they have no known competing financial interests or personal relationships that could have appeared to influence the work reported in this paper.
} 


\section{Introduction}

Over the last decades, serious concerns about air quality, water pollution, deforestation and, most importantly, the debate about climate change have led to the implementation of a wide range of environmental policies in various parts of the world (e.g. command and control-policies, environmental taxes, or pollution permit systems). In Europe, this has resulted in a steady increase of environmental policy stringency as one can see, for example, by the OECD's environmental policy stringency index shown in Figure 1.

Figure 1: Environmental Policy Stringency in Europe

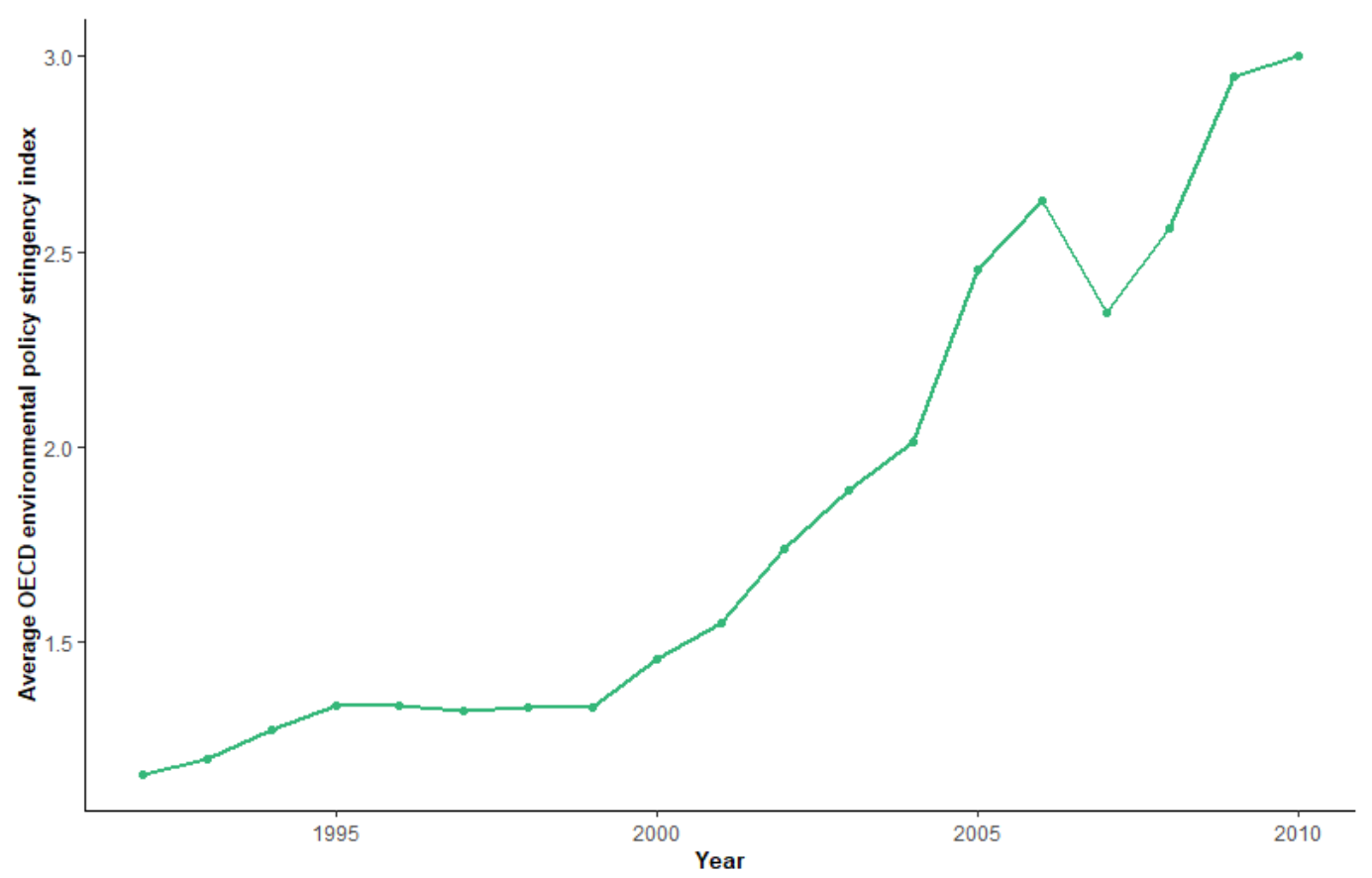

Note: Environmental policy stringency is calculated as the mean of the OECD environmental policy stringency index for 19 European countries. The index is described in more detail in the data section of this paper.

Numerous empirical studies have since investigated the effect of environmental policy changes on employment or on competitiveness and innovation. ${ }^{1}$ This literature suggests that environmental policies have had a negligible or even positive net effect on aggregate. However, even if net effects were estimated to be negligible or slightly positive, there may still be substantial adjustment costs on more disaggregated levels, e.g., due to structural changes induced by environmental regulations. Notably, adjustment costs could be particularly relevant for a significant fraction of occupations (see e.g. Walker, 2013).

Vona et al. (2018) have recently made an important contribution in this regard. Contrary to previous approaches (e.g. Bowen et al., 2018; Consoli et al., 2016), Vona et al. (2018) focus on analyzing the demand for "green skills" rather than on estimating employment shares of green or

\footnotetext{
${ }^{1}$ Some contributions focusing on employment include e.g. Marin and Vona (2019); Vona et al. (2018); Isen et al. (2017); Yamazaki (2017); Walker (2013); Cole and Elliott (2007); Berman and Bui (2001a). In turn e.g. Franco and Marin (2017); Cai et al. (2011); Berman and Bui (2001b) among others, have primarily investigated the context of innovation and productivity.
} 
green rival jobs. In order to identify green skills, they construct skills-based "greenness"-measures, which they call "green general skills" (GGS). These measures are occupation-specific indicators of how important green skills are in a given occupation. With this, Vona et al. (2018) can then describe the skill-content of occupations and analyze differences in the skills-sets between occupations. For the U.S., they show that over the period 2006-2014, environmental regulations had no causal effect on aggregate manufacturing employment, but raised the demand for green skills. In other words, they find heterogeneous effects of environmental policies in favor of occupations with a relatively high number of green skills.

Such heterogeneous effects on the occupation level are of growing concern and are intensively studied in the recent literature on the effects of technical change. For example, Autor and Dorn (2013) have shown that computerization has resulted in differential labor market responses on the occupation level. Specifically, they show that U.S. labor demand has increased not only for high-skilled occupations but also for low-skilled workers who are employed in manual task intensive service occupations. In contrast, the demand for low-skilled workers engaged in nonservice occupations with mostly routine tasks has contracted. Autor and Dorn (2013) show that these heterogeneous responses to structural changes (in the form of routine biased technical change) had strong distributional consequences between occupations and can well explain the polarization of the U.S. labor market between 1980 and 2005. Building on this, Goos et al. (2014) have investigated the phenomenon of job polarization in Europe and confirm that it was also pervasive in 16 European countries between 1993 and 2010. What both of these authors thus suggest is that whenever we want to study the effects of structural changes, we should take occupation-level adjustments into account. And as, for example, Vona et al. (2018) and Martinez-Fernandez et al. (2010) argue, the green transition can be thought of as an important structural change, triggering major shifts in the demand for occupations, tasks and skills. However, apart from the analysis of Vona et al. (2018) with U.S. data, there is little empirical evidence on the effect of this transition at relatively detailed occupational levels.

This is where our paper contributes to the literature. In particular, we use a data-driven approach to estimate the "green potential" of occupations, which we define as their potential to perform green tasks. We follow Vona et al. (2018) and argue that skills are what matters most for the green potential. In other words, an occupation that possesses many (few) skills that are important (unimportant) to perform green tasks, has a high (low) green potential. In particular, following Rutzer et al. (2020), we use data on skills and tasks from O*NET and train a machine learning algorithm that relates skills to tasks to estimate the green potential of occupations. We then use this information to investigate the relationship between environmental regulations and occupation-level employment in the manufacturing sector of 19 European countries for the period 1992-2010.

Besides Vona et al. (2018), the paper that is most closely related to ours is Marin and Vona (2019). These authors study employment effects resulting from higher energy prices across macrooccupational groups in Europe. They find heterogeneity between these occupational groups and show that technical occupations tend to win, while manual workers seem to lose from higher energy prices. With our paper, we complement their analysis by focusing on a more detailed level 
of occupations in Europe. Thus, our main contribution to the literature is twofold: First, we extend Vona et al. (2018)'s skills-based analysis of the U.S. labor market to European occupations. This provides additional support regarding the external validity of empirical findings from previous studies (e.g. Vona et al., 2018). Second, we explicitly investigate heterogeneous labor demand responses from environmental policies in Europe on a relatively disaggregate level.

For our empirical analysis, we choose a fixed effects model, where our outcome variable is occupation-level manufacturing employment and our main explanatory variable is an index of environmental policy stringency (EPS) for 19 European countries between 1992 and 2010. The EPS index incorporates a broad range of environmental policies. It has been developed by the OECD and has since been used by researchers to estimate effects of environmental policies (e.g. Marin and Vona, 2019; Verdolini et al., 2018; Albrizio et al., 2017). We choose the fully specified EPS index as the explanatory variable in our main regression models because it captures the full spectrum of environmental regulations. However, we also present estimates with sub-indices to test the robustness of our main findings. We estimate several model specifications to control for omitted variables bias and we take into account that differences in environmental policy stringency could, at least partially, result from country-specific preferences. If these preferences are related to occupational patterns in the manufacturing sector, our model could suffer from simultaneity concerns. To control for this possible bias, we also perform an instrumental variable (IV) estimation. Similar to the approach by Franco and Marin (2017), we use the cross-country average of foreign environmental policy stringency as an instrument for domestic environmental policy stringency.

For the manufacturing sector, our results indicate that an increase in environmental policy stringency has on average no significant effect on employment. This finding is consistent with previous studies (e.g. Vona et al., 2018). However, occupation-specific effects vary substantially with respect to the green potential of occupations. The higher the green potential of an occupation, the less negative the effect of environmental policy. For occupations with the highest green potential values, we estimate positive employment effects. We show that this also translates to heterogeneous effects of environmental regulations on the country level. Because policy effects vary between occupations and because the occupational structure between countries differs, countries can be winners or losers as a result of tighter environmental policies.

The remainder of this paper is structured as follows: Section two illustrates our approach to identify the green potential of occupations based on skills and tasks. It presents how we empirically construct a measure for the green potential of ISCO occupations. Section three states our empirical strategy to estimate the relationship between environmental policy stringency and occupational employment. Section four describes the data we use for the estimation. In Section five, we start by descriptively illustrating the relationship between green potential, environmental policy stringency and employment. Subsequently, we present our empirical results, show robustness checks and discuss the implication of our results. Section six summarizes the paper, relates our results to the literature and concludes. 


\section{The Green Potential of Occupations}

In this paper, we analyze the relationship between environmental policies and occupational employment changes in the manufacturing sector. As a starting point, it is important to note that the empirical literature concerned with the topic has demonstrated well that environmental policies can both create and destroy jobs in manufacturing. ${ }^{2}$ Further, some authors have argued that whether an occupation is positively, negatively or not at all affected by environmental policies primarily depends on the skills workers possess (Vona et al., 2018). This is because skills are what matters most for the potential of an occupation to perform green tasks. In other words, the skill-set of an occupation defines its green potential, which, in turn, determines whether and how an occupation is affected by environmental regulation. Therefore, one would expect heterogeneous labor market responses between occupations.

One mechanism for such employment changes is through shifts in the demand for tasks. More specifically, as environmental policy becomes more stringent, pollution abatement and energy saving measures become relatively more attractive for firms. As a result, relative demand for occupations that possess skills to perform these green tasks increases. An example would be Environmental Engineers. According to the O*NET database, a source for job descriptions, their tasks can include, for example, to "design pumping systems, pumping stations, pipelines, force mains, or sewers for the collection of wastewater". A relative increase in the demand for such green tasks would then cause heterogeneous labor demand responses to environmental regulations between occupations. Another possible channel is the task content of the occupations themselves. Occupations with few or no green tasks could be required to increasingly adapt such tasks. However, this is only possible if workers have skills that are suited to perform green tasks. If this is the case, relative labor demand would also increase for occupations that have the necessary skills to adapt green tasks. An example for such an occupation could be Industrial Production Managers. Again, according to $\mathrm{O}^{*} \mathrm{NET}$, they are currently not explicitly involved in any specific green tasks. However, they could be in the future and if this were to happen, it would again result in heterogeneous labor demand effects from environmental policy. ${ }^{3}$

In order to empirically examine these responses, we need a measure that approximates an occupation's potential to perform green tasks based on its skills (i.e. an approximation of its green potential). The crucial part of this is how to relate skills to green tasks. In principle, there are numerous possible ways. Vona et al. (2018) were, to the best of our knowledge, the first to propose a technical approach to the problem. Using data from $\mathrm{O}^{*} \mathrm{NET}$, they fit an OLS model to identify a subset of skills which are important to perform green tasks. ${ }^{4}$ As the number of important skills is

\footnotetext{
${ }^{2}$ The debate on net effects from environmental regulation started at the latest with Porter and van der Linde (1995). For an overview of the relevant literature see e.g. Vona et al. (2018) or Bowen and Kuralbayeva (2015).

${ }^{3}$ In the long run, there is also a more aggregate structural change that is induced by environmental policy: As polluting becomes more costly, the relative prices of goods and services change. However, we do not discuss such long run general equilibrium effects. Instead, we follow the empirical literature (see e.g. Marin and Vona, 2019; Vona et al., 2018; Franco and Marin, 2017; Leiter et al., 2011) and limit our analysis to the manufacturing sector. That is to say, our empirical approach focuses on supply side effects of environmental policy stringency in the short run and our findings are not to be interpreted as long-term general equilibrium effects (for more information see e.g. Cainelli and Mazzanti, 2013; Greaker, 2006).

${ }^{4}$ To be more specific, Vona et al. (2018) classify skills with a positive and at the $99 \%$ level statistically significant coefficient as important to perform green tasks.
} 
rather large, they apply principal component analysis (PCA) to group these skills into four different "greenness measures" which they call "Green General Skills" (GGS). Subsequently, it is possible to evaluate the importance of a GGS (i.e. selected green skills) in any given occupation. As their GGS indices are based on skills that are important for green tasks, they could, in principle, also be interpreted as a measure of green potential. However, Vona et al. (2018) consider a subset of skills and they use unweighted averages of these skills for their GGS measures. If we used their GGS measures as direct approximations for the green potential of occupations, this could be misleading. Rutzer et al. (2020) propose a different approach by predicting the green potential of occupations based on their entire skills sets. In doing so, they have trained different machine learning algorithms and compared their performance. It turned out that the Ridge regression showed the best goodness of prediction among all trained algorithms, including the GGS proposed by Vona et al. (2018). Hence, we follow Rutzer et al. (2020) and use the Ridge regression to determine the green potential of occupations in Europe. In the remainder of this section, we outline the approach in more detail.

\section{Predicting the Green Potential of Occupations}

In our analysis, we use occupations that are classified according to the International Standard Classification of Occupations (ISCO). The ISCO is a classification system of occupations developed by the International Labor Organization (ILO). It has been under major revisions over time, whereas the latest version is ISCO-08. In our analysis, we stick to the previous ISCO nomenclature of the year 1988 (ISCO-88), as it allows us to consider the largest number of observations for our empirical analysis. We will come back to this in Section 4. Unfortunately, to the best of our knowledge, there exists no information about the green potential of occupations classified according to ISCO-88 (or ISCO-08). However, it is possible to exploit U.S. data provided by $\mathrm{O}^{*}$ NET to estimate the green potential of ISCO occupations. ${ }^{5}$ In doing so, we proceed in two steps. In the first step, we use $\mathrm{O}^{*} \mathrm{NET}$ data to train a model that allows us to predict the green potential of U.S. SOC occupations. In the second step, we transfer data from SOC to ISCO occupations and use it as input for the model trained on U.S. data to estimate the green potential of ISCO occupations. In what follows, we describe the two steps in more detail.

For the first step, two pieces of information from O*NET (version 22.1) are of particular interest. First, O*NET contains information on the relative number of green tasks for a total of 966 U.S. occupations. Second, for each occupation there exists information about its "Knowledge" (based on 33 different items), "Work activities" (based on 41 different items), "Work values" (based on 6 different items) and "Skills" (based on 34 different items). For all of these items, O*NET reports a value between 1 (lowest) and 5 or 7 (highest) for its importance and required level in every occupation. Vona et al. (2018) have argued that combining these item categories well describe the skills and knowledge that are required to perform the tasks of a certain occupation. We follow these authors and thus define the above-mentioned 114 items as our list of important occupational skills. With these pieces of information at hand, it is possible to train machine learning algorithms

\footnotetext{
${ }^{5} \mathrm{O} * \mathrm{NET}$ is a database sponsored by the U.S. Department of Labor. It contains a huge amount of information on occupations. We refer interested readers to Dierdorff et al. (2009) for a more detailed description of the O*NET data used in this paper. Moreover, other work analyzing the green potential of the U.S. labor market also builds on information from O*NET (Vona et al., 2018; Bowen et al., 2018; Consoli et al., 2016).
} 
using the skills from $\mathrm{O}^{*} \mathrm{NET}$ as explanatory variables (i.e. features) and the relative number of green tasks as the outcome variable. As mentioned above, we use the Ridge regression in this paper.

Ridge regression is an estimation method that is capable of handling situations where the data consists of few observations and many explanatory variables. In such a setting, an OLS model would usually overfit to the training data. As a result, the prediction accuracy to new data may be low. In our setting, this is relevant because we are using a rather large number of 114 skills as explanatory variables. To tackle this problem, the Ridge regression adds a penalty term to the standard OLS regression equation. The penalty term contains the sum of the squared coefficients of the input variables multiplied by an endogenously determined constant (see, for example Hastie et al., 2009). Formally, one obtains the Ridge regression coefficients by minimizing

$$
\underset{\beta}{\operatorname{argmin}} \sum_{i=1}^{N}\left(y_{i}-\beta_{0}-\sum_{s=1}^{p} s k i l l_{i, s} \beta_{s}^{\text {ridge }}\right)^{2}+\lambda^{\text {ridge }} \sum_{s=1}^{p}\left(\beta_{s}^{\text {ridge }}\right)^{2},
$$

with $y_{i}$ as the outcome variable, which, in our setup, contains the relative number of green tasks. Moreover, skill $_{i, s}$ contains a skill $s$ and $\lambda^{\text {ridge }} \geq 0$ is the penalty parameter determined later on. This optimization problem leads to the following coefficients of the Ridge regression:

$$
\hat{\beta}^{\text {ridge }}=\left(X^{\prime} X+\lambda^{\text {ridge }} I\right)^{-1}\left(X^{\prime} Y\right),
$$

where $I$ is the identity matrix, $X$ the matrix of skill values and $Y$ the vector of the relative number of green tasks. For $\lambda^{\text {ridge }}=0$, one obtains the standard OLS model. Compared to that, a positive penalty parameter shrinks the coefficients towards zero, where a larger $\lambda^{\text {ridge implies a }}$ stronger shrinkage. This has two effects. First, the shrinkage reduces overfitting to the training data, and, thus increases generalization to new data. Or in other words, it reduces the probability of learning too many patterns specific to the training data. At the same time, however, this may increase the error due to learning an incorrect relationship between input variables and the response variable. Due to these opposite effects, an increase in $\lambda^{\text {ridge }}$ leads to a trade-off influencing the goodness of prediction in either a positive or negative direction. We apply a tenfold cross-validation to find a value for $\lambda^{\text {ridge }}$ that leads to the best prediction within our data. This means we randomly split our $\mathrm{O}^{*} \mathrm{NET}$ observations into ten similar-sized sets, left the first, second, ..., 10th data set out and train the model on the remaining nine sets, respectively. Using each left out fold, one can calculate the mean squared prediction error (MSPE) for each trained model. We repeat these steps for several different values of $\lambda^{\text {ridge }}$ and choose the penalty parameter associated with the lowest MSPE. As usual in machine learning, we use this penalty parameter to train the final model by considering all observations.

To train the Ridge regression algorithm, we use the previously described data from O*NET. In particular, we use the relative number of green tasks to all tasks an occupation performs as a response variable and the 114 skills as input variables. We standardize each occupation's skill 
value by subtracting the skill's mean and dividing it by the skill's standard deviation. ${ }^{6}$

Once the model has been trained, it can be used to predict the green potential of an occupation:

$$
\hat{\eta}_{i}=\hat{\beta}_{0}+\sum_{s=1}^{p} s k i l l_{i, s} \hat{\beta}_{s}^{r i d g e}
$$

In the next step, we assign skill values to ISCO occupations. It is then possible to predict the green potential of ISCO occupations using Equation (2). ${ }^{7}$

Several studies confirm that the skills requirements of occupations in the U.S. labor market are similar to those of comparable occupations in other industrialized countries (OECD, 2017; CEDEFOP, 2013). Thus, using skills from $\mathrm{O}^{*} \mathrm{NET}$ and transferring them to ISCO occupations seems a valid approach. In doing so, we follow the literature (OECD, 2017; Goos et al., 2014) and transfer the skills step by step from SOC-8 to SOC-6, then to ISCO-08 and finally to ISCO-88. At each step, we apply a simple average. A detailed explanation of our procedure can be found in the Appendix A.1. Using the so-obtained skill values as input in Equation (2) allows us to predict the green potential $\hat{\eta}_{i}$ of 3 -digit ISCO-88 occupations. As the Ridge regression is a linear estimation method, predictions can also have negative values. This is not very suitable in the context of green potential, because an occupation's potential to perform green tasks should obviously be at least zero. Rutzer et al. (2020) argue that normalizing all green potential predictions on a 0-1 scale best solves this issue. In a final step, we thus follow this approach and normalize the 3-digit ISCO-88 predictions from Equation (2). This delivers our final occupation-level indicator of green potential. Considering all 101 ISCO 3-digit occupations, the mean green potential value is 0.34 and the standard deviation is $0.21 .^{8}$ To illustrate, Table 1 states the three manufacturing occupations with the highest and lowest green potential, respectively. Table 10 in the Appendix reports a full list of all 3-digit ISCO-88 occupations.

Table 1: Top and Bottom Green Potential Estimates

\begin{tabular}{llr}
\hline ISCO & Occupation & Green Potential \\
\hline 211 & Physicists, chemists and related professionals & 1.00 \\
214 & Architects, engineers and related professionals & 0.96 \\
712 & Building frame and related trades workers & 0.77 \\
$\ldots$ & $\ldots$ & $\ldots$ \\
414 & Library, mail and related clerks & 0.08 \\
411 & Secretaries and keyboard-operating clerks & 0.01 \\
422 & Client information clerks & 0.00 \\
\hline
\end{tabular}

\footnotetext{
${ }^{6}$ Following common recommendations (see, for example, Hastie et al., 2009), we standardize only the explanatory variables and leave the response variable unchanged. This means, our response variable is in the range of 0 (no green task is performed) and 1 (all performed tasks are green).

${ }^{7}$ In general, the parameters of the Ridge regression are not consistent and therefore cannot be interpreted in the same way as e.g. conventional OLS regression coefficients. However, to get an idea which parameters are important for our estimates of the green potential, we have included them in the Appendix 9.

${ }^{8}$ In our empirical analysis, some of these occupations drop out of the sample because there are no such jobs in the manufacturing sector. If considering only those occupations we also use for the empirical analysis, the sample mean is 0.37 and the standard deviation 0.2 .
} 


\section{Estimating Heterogeneous Labor Market Responses}

In the last section we have presented our approach to capture the heterogeneity of occupations with respect to their green potential. With this data, we can now investigate if demand responses following environmental policy changes differ among occupations. In what follows, we present our empirical strategy to estimate such heterogeneous effects. We begin by stating our empirical model:

$$
\log e m p_{i j t}=\beta_{1} E P S_{j, t-1}+\beta_{2} \hat{\eta}_{i} E P S_{j, t-1}+\gamma \mathbf{X}_{j, t-1}+\text { strend }_{j}+\tau_{t}+v_{i j}+u_{i j t} .
$$

In this fixed effects model, $\log e m p_{i j t}$ is the $\log$ of employment of occupation $i$ in country $j$ at time $t$ and $E P S_{j, t-1}$ indicates lagged environmental policy stringency in country $j$ at time $t-1$. Following previous studies investigating effects of environmental policies, we use a one-period lag for our environmental policy variable (e.g. Franco and Marin, 2017; Leiter et al., 2011; Jaffe and Palmer, 1997). This lag structure allows the employment response to occur after some time and, at the same time, reduces simultaneity concerns (Franco and Marin, 2017; Leiter et al., 2011). ${ }^{9}$

$\hat{\eta}_{i}$ is the occupation-specific measure of green potential estimated with the Ridge regression. In our empirical setting $\hat{\eta}_{i}$ captures the heterogeneity between occupations in terms of their green potential. ${ }^{10} \mathbf{X}_{j, t-1}$ is a vector of control variables, which takes into account country-level business cycles, labor force characteristics, trade openness and general technological trends. We follow the literature and include all control variables with a one-period lag. The variable trend $_{j}$ additionally controls for country-specific linear time trends and $\tau_{t}$ are year dummies that control, e.g. for shocks that are common to all countries. Moreover, $v_{i j}$ are occupation-country fixed effects that take into account occupation-country specific characteristics. For example, $v_{i j}$ captures the absolute value of occupational green potential $\hat{\eta}_{i}$. This is also the reason why Equation 3 does not include a term $\hat{\beta}_{3} \hat{\eta}_{i}$, which would automatically cancel out with $v_{i j}$ also being part of the model. Finally, $u_{i j t}$ is the error term of the model.

$\beta_{1}$ and $\beta_{2}$ are parameters to be estimated to capture the effect of environmental policy stringency. To interpret the two $\beta$-coefficients, recall that the green potential measure $\hat{\eta}_{i}$ is normalized among occupations between 0 and 1 . Thus, the estimated effect of a one-unit increase in $\hat{\eta}_{i}$ conditional on a marginal increase in environmental policy stringency $E P S_{j, t-1}$ has an interesting implication: It is identical to comparing the effect of a marginal increase in environmental policy stringency on the top-ranked green potential occupation (with $\hat{\eta}_{t}=1$ ) versus the effect on the bottom-ranked occupation (with $\hat{\eta}_{b}=0$ ). Thus, $\beta_{1}$ states the effect of a marginal increase in environmental policy stringency on employment for the bottom-ranked occupation. And adding $\beta_{2}$ to

\footnotetext{
${ }^{9}$ As a check to the sensitivity of this regression specification, we have also tested our empirical model with alternative lag structures. This did not change our empirical findings (see Table 18 in the Appendix). Furthermore, we have estimated regression models using 3-year and 4-year period averages instead of annual changes. It is reassuring that our baseline estimates also remain robust against this alternative model specifications (see Table 21 in the Appendix).

${ }^{10}$ Similar to e.g. it's routine-task intensity, an occupation's green potential could, in principle, change over time. Such a change would not be directly captured by $\hat{\eta}_{i}$. This is a shortcoming of our empirical strategy, which, however, we have in common with many studies focusing on technical change or offshoring (e.g. Gregory et al., 2018; Autor and Dorn, 2013; Blinder and Krueger, 2013). Nevertheless, such changes would still be captured by the model's time-fixed effects if the change is not biased against some specific occupations.
} 
$\beta_{1}$ captures the effect on the top-ranked occupation. Hence, $\beta_{1}$ and $\left(\beta_{1}+\beta_{2}\right)$ indicate the range of the estimated occupational employment effects. In turn, by setting $\beta_{2}$ to zero and estimating Equation (3) again, $\beta_{1}$ captures the average effect of environmental policy across all occupations.

Our empirical specification may suffer from various identification problems. One concern is omitted variables bias, which is always an issue when working with observational data. Omitted variable bias would distort our empirical results if variables existed which affect occupational employment, are correlated with our main explanatory variable $E P S_{j, t-1}$ and are unobserved or not sufficiently controlled for in our regression model. A fixed effects model reduces this concern to some extent, because it automatically takes into account all potentially distorting variables that do not vary over time (i.e. $v_{i j}$ in Equation 3). Such fixed effects are, for example, the general offshorability or routine task intensity of occupations. In addition to controlling for such fixed effects, we also include time trends and a wide range of control variables into our model. Finally, we explicitly investigate some potential sources of omitted variable bias in more detail in a sensitivity analysis.

A second problem of our model is that it could suffer from reverse causality. Reverse causality could be an issue if occupational patterns in the manufacturing sector have an effect on countrylevel environmental regulations. This could, for example, be the case through political preferences or lobbying. At first sight this scenario does not seem to be a major issue, because our model features employment on the occupation level and not on the industry level. Hence, it seems rather unlikely that occupation-level employment changes (e.g. employment changes for "machine operators" in the manufacturing sector) directly influence national environmental regulations. In contrast, measuring employment at the industry level would make reverse causality, e.g. through lobbying, a much bigger threat to the validity of our estimates. Moreover, all of our explanatory variables are included in the model with a one-period lag. For simultaneity to occur, future occupational employment changes would have to affect current environmental policies. Because occupational groups could anticipate future employment effects and thus influence the current political process, this is not impossible. However, the problem is somewhat reduced by the lag structure of our model. Nevertheless, we additionally use an instrumental variable approach to further address simultaneity concerns. In doing so, we use average foreign environmental policy stringency as an instrument for domestic policy stringency. This is a similar approach as, e.g. in Franco and Marin (2017). These authors investigate the effect of environmental policy on innovation and productivity. In order to estimate causal effects of policy changes on productivity, they instrument a sector's patent stock by using the average patent stock of the same sectors in foreign countries as well as the average patent stock of other domestic sectors. Regarding the validity of our instrument, our main assumption for the exclusion restriction to hold is that occupationlevel employment patterns are only affected by the foreign level of environmental policy stringency through domestic policy stringency (e.g. through international agreements or EU directives as a tool to harmonize stringency across EU countries). In other words, e.g. domestic preferences and 
lobbying are assumed to have no effect on average foreign environmental policy stringency. ${ }^{11}$ Given this assumption, instruments for environmental policy in country $k$ at time $t$ can be constructed as the mean of all other $N-1$ countries' environmental policy stringency:

$$
E P S_{k t}^{I V}=\frac{1}{N-1} \sum_{j=1}^{N-1} E P S_{j t} \quad \forall j \neq k .
$$

Using $E P S_{j t}^{I V}$ as an instrument for $E P S_{j t}$ in Equation (3) allows us to re-estimate our model with an instrumental variable approach.

\section{Data}

In this section we provide an overview of the data we use to estimate our empirical model. We begin by describing the data on environmental policy stringency. We then turn to the data on occupation-level manufacturing employment, which is our outcome variable of interest. Lastly, we present information on the variables that we use as controls.

\section{Environmental Policy}

As for any empirical study assessing quantitatively the effects of environmental regulations, a key challenge is to find some exogenously determined measure of environmental policy stringency. For the U.S., many studies have used the Clean Air Act (CAA) and its amendments (CAAA) (see e.g. Vona et al., 2018; Isen et al., 2017; Chay and Greenstone, 2003; Greenstone, 2002). Unfortunately, similar policy experiments are hard to find in Europe. Therefore, studies on European environmental regulations have to resort to a more general approach to measure environmental stringency. For example, Cole and Elliott (2007) focus on environmental protection expenditure, Franco and Marin (2017) on environmental taxes and, more recently, Marin and Vona (2019) use energy prices. In our analysis, we use the OECD's recently developed environmental policy stringency (EPS) index (Botta and Koźluk, 2014). This indicator has already been used in some empirical studies on environmental regulations (see e.g. Marin and Vona, 2019; Verdolini et al., 2018; Albrizio et al., 2017). One of its main advantages is that it allows a comparison of environmental policy stringency on the international level over a relatively long period of time. At the same time, the EPS aggregates a wide range of environmental policies and does not focus on a very specific policy intervention. This also means that all of our empirical findings are estimated with respect to the overall green regulatory stringency and not with regard to some clearly identified and unique policy introduction.

The EPS index is a composite indicator constructed from a set of environmental policies that explicitly or implicitly raise the cost of polluting or environmentally harmful behaviour (Botta and Koźluk, 2014). The included policy instruments range, e.g. from emission trading schemes for $\mathrm{CO}_{2}$

\footnotetext{
${ }^{11} \mathrm{~A}$ related challenge to the validity of our instrument could be a possible negative influence of foreign environmental regulations on the competitiveness of the respective countries. The domestic country could then gain market shares, leading to a potential failure of the exclusion restriction. Unfortunately, this potential fallacy cannot be tested and ruled out empirically. However, given that substantial shifts in production generally require some time, our empirical strategy should mitigate this concern to some extent.
} 
to $\mathrm{SO}_{x}$ emission limits and industry taxes on diesel. With this broad approach, the EPS index allows an approximation of the multi-dimensionality of environmental policy. From a technical point of view, the index is constructed along the following lines: First, the stringency of every national policy instrument at any point in time (e.g. $\mathrm{SO}_{x}$ emission limits in Germany in the year 2002) is defined using a cardinal measure of 7 classes. Each class receives a scoring value, which ranges from 0 (non-existent) to 6 (most stringent). For every policy instrument, the boundaries of these seven classes are then defined, based on the full sample distribution of the policy instrument in question. For example, an emission limit value (ELV) for $\mathrm{NO}_{x}$ between 200 and $250 \mathrm{mg} / \mathrm{nm}^{3}$ is assigned to the 5th class. This class has a scoring value of 4, i.e. an ELV of $220 \mathrm{mg} / \mathrm{nm}^{3}$ would receive a policy stringency value of 4 . In other words, the more stringent a specific policy instrument is in relative terms, the higher its EPS. By averaging the scoring values of different policy instruments, one obtains the EPS index. In fact, there are several EPS sub-indicators for different levels of aggregation. For our analysis, we choose the fully specified EPS index on the country-level, because it best approximates the broad range of policies which is inherent to a green transition. ${ }^{12}$

Over the next section of this paper, we present our regression results and additionally illustrate employment responses from a specific regulatory shock. In order to derive and quantify such a policy shock, we will use the distribution of the EPS index, instead of just choosing an arbitrary figure. In particular, we use the following definitions: We define $E P S_{j,}$, as the country-level average EPS index over time and $E P S_{., .}$as the mean of all $E P S_{j, .}$. Notation-wise, a dot in the subscript indicates the dimension(s) on which we average over. Formally:

$$
\begin{gathered}
E P S_{j, .}=\frac{1}{T} \sum_{t=1}^{T} E P S_{j, t} \\
E P S_{., .}=\frac{1}{J} \sum_{j=1}^{J} E P S_{j, .}=1.9
\end{gathered}
$$

To describe the evolution of the EPS index, we similarly define $\Delta_{j, .}^{E P S}$ as a country-level average of EPS-changes over time and $\Delta_{\text {.,. }}^{E P S}$ as the mean of all country-level average EPS-changes:

$$
\begin{gathered}
\Delta_{j, .}^{E P S}=\left(\prod_{t=2}^{T} \frac{E P S_{j, t}}{E P S_{j, t-1}}\right)^{\frac{1}{T-1}}-1 \\
\Delta_{., .}^{E P S}=\frac{1}{J} \sum_{j=1}^{J} \Delta_{j, .}^{E P S}=0.0691
\end{gathered}
$$

The initial values $E P S_{j, 1}$ and, especially, the evolution of the EPS, is heterogeneous across countries. ${ }^{13}$ This is clearly shown in Figure 2, which plots $\Delta_{j, .}^{E P S}$ i.e. the country-level average

\footnotetext{
${ }^{12}$ For detailed information on all the policy instruments included in this EPS specification, see Botta and Koźluk (2014). As a robustness check, we have also estimated our baseline regression model using sub-indicators of the EPS as explanatory variables. This did not change our overall empirical findings (see Table 22 in the Appendix).

${ }^{13}$ Note that the range of our sample varies slightly among countries. Table 11 in the Appendix presents summary statistics as well as the time range for the EPS index of every country in our estimation sample.
} 
of EPS-changes over time. It is interesting to see that the three Eastern European countries of Hungary, Slovakia and the Czech Republic have witnessed the largest average changes over the sample period ranging from 1992-2010. This could be due to their accession to the European Union in 2004, which could have triggered many regulatory shocks in these countries. In turn, countries like Germany, Denmark or Switzerland, which already had a rather high initial environmental policy stringency in our sample, did not experience large EPS-changes on average. Thus, regarding the validity of our estimates, it will be important to consider if estimated policy effects are driven solely by the evolution of environmental policy stringency of specific countries.

Figure 2: Average environmental policy stringency changes over time

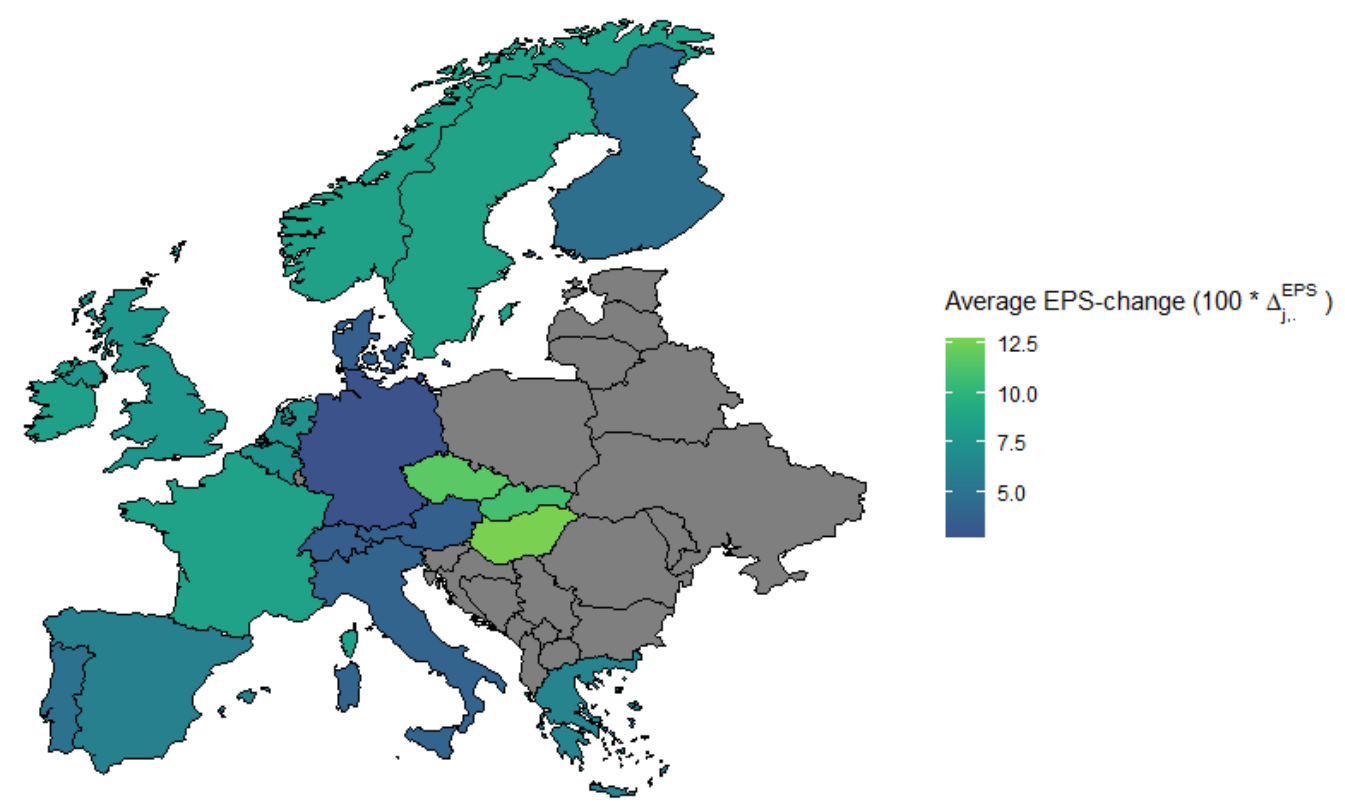

Note: The country-level averages $\Delta_{j . .}^{E S}$ are calculated as the geometric mean of EPS-changes over time. The data is from the OECD and covers the period 1992 to 2010. European countries, which are not part of our analysis, are colored in gray.

\section{Employment}

For the number of employed persons in different occupations and countries, we use data from the European Labor Force Survey (ELFS) from Eurostat. The representative survey has been conducted since 1983 in all EU member states, plus Iceland, Norway and Switzerland by the respective domestic statistical offices and harmonized by Eurostat. The data is widely used for different purposes. For example, Eurostat uses the data for their employment and unemployment figures of European countries. Moreover, the data has also been used in various scientific publications (see, for example, Gregory et al., 2018; Goos et al., 2014, 2009). For this paper, we use the data to calculate the number of persons of a country employed in a particular occupation and industry on a yearly base. In particular, we use occupations categorized according to ISCO-88. This allows 
us to consider data from 1992 to 2010 of the ELFS. If instead we used the latest revision of the ISCO, namely ISCO-08, the data would be available for the period 2011-2016 only. Hence, by using ISCO-88 it is possible to consider a much longer time period. Moreover, in order to have as many different occupations as possible, we take only those countries into account that report the employment numbers on a 3-digit ISCO level, which is the most disaggregated level available in the ELFS. All other countries are excluded. ${ }^{14}$ Moreover, as in Vona et al. (2018), we consider only employment in the manufacturing industry. In sum, our analysis considers data for a maximum of 66 different occupations in the manufacturing sector of the following 19 European countries: Austria, Belgium, the Czech Republic, Denmark, Finland, France, Germany, Greece, Hungary, Ireland, Italy, the Netherlands, Norway, Portugal, Slovakia, Spain, Sweden, Switzerland and the UK. ${ }^{15}$

\section{Control Variables}

Apart from environmental policy, various other economic and demographic trends could have an effect on occupational employment. Important drivers could be, for example, the occupation-specific routine task intensity or offshorability, technological trends like digitalization and robotization, as well as the business cycle and trade, just to name a few. Our empirical model takes this into account, as it explicitly incorporates a set of control variables for such trends. More specifically, we control for the national unemployment rate, trade openness (measured as the logged share of the sum of exports and imports over GDP), technological change and human capital (measured as the log of total patents invented by domestic residents), the female labor force participation rate and the demographic structure of an economy (measured by the ratio of persons of working age (15-64) to pension age $(+65))$ using data from the OECD. Additionally, we collect data from Eurostat for the size of the manufacturing sectors (measured as the log of total manufacturing employment) and the population size (measured as the log of total population). Summary statistics on all these control variables can be found in Table 13 in the Appendix.

\section{$5 \quad$ Empirical Results}

In this section, we first present our estimation results and subsequently show corresponding robustness checks. Before concluding, we highlight possible employment responses following an environmental policy shock and discuss the implication of our results.

As a starting point to our empirical analysis, we first provide some illustrative descriptive correlations about the potential relationship of environmental policy, employment and green potential. Figure 3 relates the three dimensions to each other. In particular, it plots the country-level averages of occupational employment changes over time $\Delta_{i_{j}, .}^{e m p}$ (in \%) relative to the country-level averages of EPS-changes over time $\Delta_{j, .}^{E P S}$ (in \%), whereas the latter are weighted by the green potential of occupations $\hat{\eta}_{i}$. The blue line is the fitted linear relationship between the two variables

\footnotetext{
${ }^{14}$ In addition, we have excluded countries that only reported employment figures for relatively few occupations. This was the case for Cyprus, Estonia, Latvia, Lithuania, Luxembourg.

${ }^{15}$ Table 12 in the Appendix reports the number of ISCO 3-digit occupations per country used for our empirical analysis.
} 
and the color of the points indicates the green potential of occupations. The figure suggests a

Figure 3: Green potential, environmental policy stringency and employment

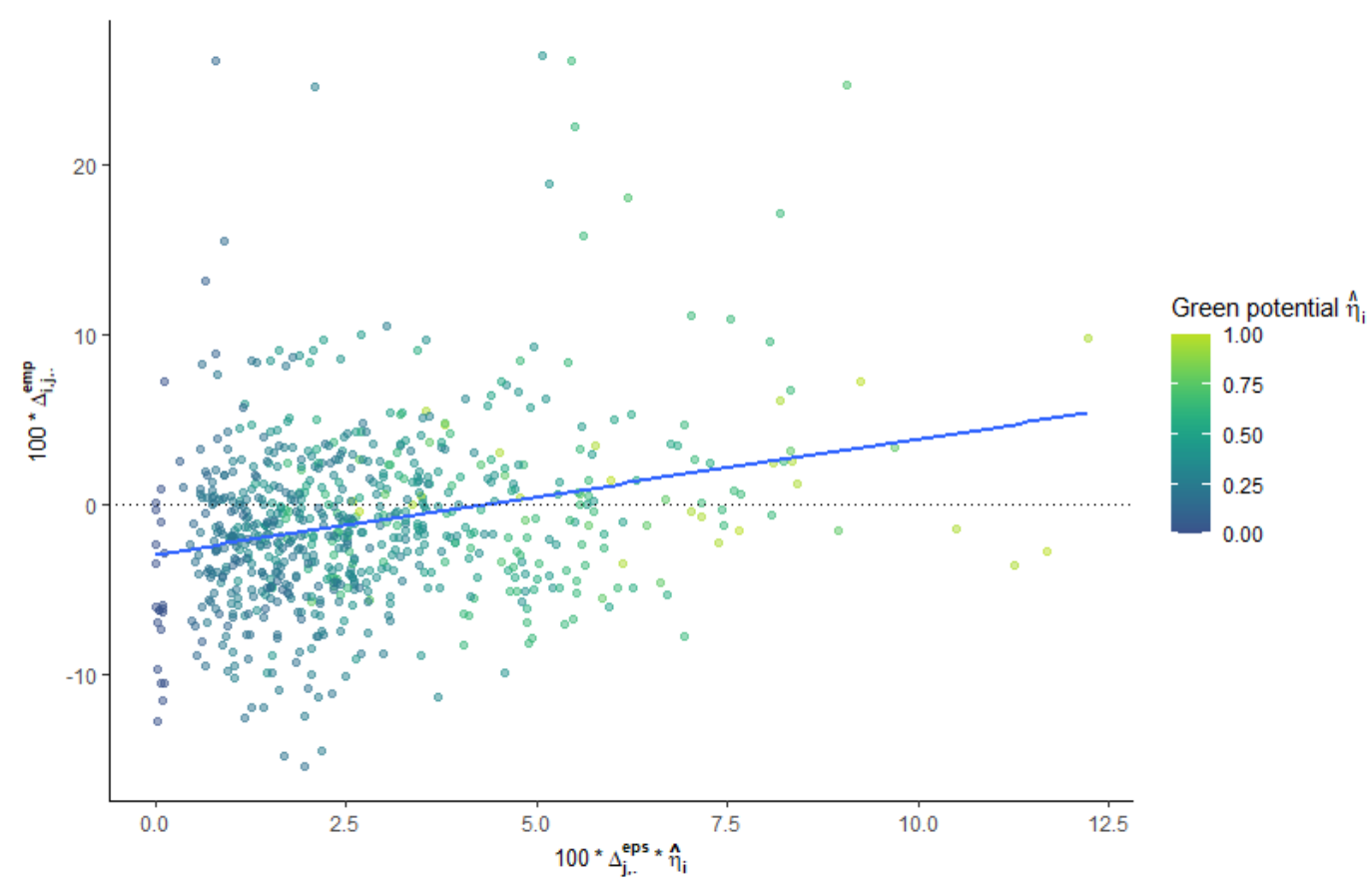

Note: Country-level average changes $\Delta_{j, .}^{E P S}$ and $\Delta_{i_{j, .}}^{e m p}$ are calculated as the geometric mean of annual changes in the EPS index and occupational employment levels, respectively. $\Delta_{j .}^{E S}$ is weighted by the green potential of occupations $\hat{\eta}_{i}$. The data on environmental policy is from the OECD and that on occupational employment from Eurostat. The data covers the period 1992-2010.

positive relationship between changes in occupational employment and environmental policy stringency weighted by green potential. In general, occupations with a lower green potential, which are colored darker in Figure 3, seem to experience smaller or even negative employment changes compared to those with higher green potential. Thus, this descriptive correlation suggests that a causal relationship, as it has been documented by Vona et al. (2018) for the U.S., could also be present in Europe. Of course, there are many other factors that simultaneously influence occupational employment changes and could drive the relationship presented in Figure 3. Thus, our empirical model stated in Equation (3) incorporates several control variables to reduce such threats from omitted variable bias. In the next subsection, we present estimation results from various specifications of our empirical model.

\section{Main Results}

We first discuss our empirical results of a fixed effects regression of the model specified in Equation (3). The results are presented in Table 2. The two coefficients on environmental policy estimate the linear relationship of a one-unit increase in the EPS index on the bottom-ranked and top-ranked 
green potential occupation, respectively. ${ }^{16}$ The coefficient in column (4) is an exception, as it states the average effect on employment across all occupations. All model specifications are estimated using a within transformation to control for time-invariant fixed effects on the occupation-country level (i.e. fixed and unobserved characteristics of occupations in a given country). Following Goos et al. (2014), standard errors are clustered at the occupation-country level and are robust against heteroskedasticity. ${ }^{17}$

Table 2: Impact of Environmental Policy Stringency on Employment (Fixed Effects)

\begin{tabular}{lcccc}
\hline \hline & \multicolumn{4}{c}{ Dependent variable: } \\
\cline { 2 - 5 } & \multicolumn{4}{c}{$\log \left(\right.$ employment $\left._{i_{j}}\right)$} \\
& $(1)$ & $(2)$ & $(3)$ & $(4)$ \\
\hline Environmental Policy ${ }_{j, t-1}$ & $-0.236^{* * *}$ & $-0.155^{* * *}$ & $-0.139^{* * *}$ & -0.009 \\
& $(0.027)$ & $(0.027)$ & $(0.030)$ & $(0.015)$ \\
Environmental Policy $j, t-1$ & $0.391^{* * *}$ & $0.377^{* * *}$ & $0.336^{* * *}$ & \\
Green Potential $\hat{\eta}_{i}$ & $(0.058)$ & $(0.057)$ & $(0.065)$ & \\
\hline Occupation-country fixed effects & $\checkmark$ & $\checkmark$ & $\checkmark$ & $\checkmark$ \\
Year dummies & & $\checkmark$ & $\checkmark$ & $\checkmark$ \\
Country time trends & & $\checkmark$ & $\checkmark$ & $\checkmark$ \\
Business cycle, trade \& technology & & $\checkmark$ & $\checkmark$ & $\checkmark$ \\
Demographic \& sector controls & & $\checkmark$ & $\checkmark$ & $\checkmark$ \\
Trade \& technology interactions & & & $\checkmark$ & $\checkmark$ \\
1-digit ISCO time trends & & & $\checkmark$ & $\checkmark$ \\
& & & & \\
Observations & 11,543 & 11,123 & 11,123 & 11,123 \\
$\mathrm{R}^{2}$ & 0.046 & 0.072 & 0.113 & 0.105 \\
Adjusted R ${ }^{2}$ & -0.018 & 0.007 & 0.050 & 0.041 \\
\hline \hline
\end{tabular}

Notes: The sample is an unbalanced panel that covers 19 European countries between 1992 and 2010. The dependent variable in all columns is the log of occupational employment. All model specifications include fixed effects for country-specific occupations. Columns (2) to (4) further include year dummies, country-specific linear time trends and a set of control variables. More specifically, columns (2) to (4) include the national unemployment rate, the logged share of exports plus imports over GDP and the logged patent stock invented by domestic residents to control for the business cycle as well as trends in trade and technology. Demographic and sector controls consist of the following variables: The working age (16-64 years old) to pension age (65 years and older) ratio, the female labor force participation rate, the $\log$ of the total population and the log of total manufacturing employment. In columns (3) and (4) the trade and technology control variables from column (2) are additionally interacted with the green potential measure $\hat{\eta}_{i}$, thereby constructing two new controls on the occupation level. Moreover, columns (3) and (4) incorporate a linear time trend on the 1-digit ISCO level. Data is from the OECD and Eurostat. Standard errors in parentheses are clustered at the level of country-specific occupations (721 country-specific ISCO 3-digit occupations) and are robust against heteroskedasticity. Significance levels for the coefficients are indicated as: ${ }^{*} \mathrm{p}<0.1 ;{ }^{* *} \mathrm{p}<0.05 ;{ }^{* * *} \mathrm{p}<0.01$

In column (1) we estimate the model without any control variables. This yields two highly significant coefficients for both the top- and bottom-ranked green potential occupation. For the

\footnotetext{
${ }^{16}$ We have also estimated a model that includes the square of the EPS index as an explanatory variable. Using such a specification results in the same estimated relationship as it is discussed over the following sections. However, point estimates vary and generally become larger in absolute size compared to the pure linear relationship. At the same time, standard errors increase and the relationship becomes less stable.

${ }^{17}$ Coefficients and standard errors on all included variables in the model specifications presented in Table 2 can be found in Table 14 in the Appendix
} 
bottom-ranked occupation, we estimate a negative and for the top-ranked occupation a positive employment response. These coefficients highlight the employment effect associated with a oneunit increase in the EPS index. In order to illustrate and discuss occupational employment changes, we use an average EPS-change. To derive it, recall the definitions from Section 4: $\Delta_{\text {,., }}^{E P S}=0.069$ or $6.9 \%$ is the mean of country-level averages of EPS-changes over time. Similarly, $E P S_{\text {... }}=1.9$ is the mean of country-level averages of EPS levels over time. Based on this, an average EPS-change across countries can be approximated by $\Delta_{., .}^{E P S} \times E P S_{., .}=0.069 \times 1.9=0.131$. Multiplying this figure by the $\hat{\beta}$-coefficients from column (1) implies the following: In response to an average EPSchange by 0.131 , employment decreases by $3.1 \%$ for the bottom-ranked occupation and increases by $2.0 \%$ for the top-ranked occupation, respectively. ${ }^{18}$ However, this model specification only controls for occupation-country specific effects that do not vary over time (e.g. the routine task intensity or the offshorability of occupations). Therefore, the estimates are likely to suffer from omitted variable bias resulting from, e.g. general economic conditions and structural trends.

To address this issue, we add in column (2) year dummies, country-level time trends and seven control variables. Three of the control variables embody general economic trends. More precisely, they control for changes in the national unemployment rate, changes in a country's openness to foreign trade (measured as the logged share of the sum of imports and exports on GDP) and in its total patent stock (measured as the log of the total number of patents invented by its residents). The four remaining control variables address omitted variable bias, which could result from country-level demographic dynamics or trends that are specific to the manufacturing sector. An important issue could, for example, be migration flows resulting from more stringent environmental policies in some specific countries. To address such trends, we add the share of the working age population (16-64 years old) relative to the share of pensioners (65+ years old) as a proxy for the age structure of an economy and we also include the female labor force participation rate. Further, we include the log of the country's population and the log of total manufacturing employment. Controlling for year dummies, time trends and these seven control variables decreases the coefficient on the bottom-ranked occupation in column (2) but leaves the top-ranked occupation practically unaffected. Also, both coefficients remain highly significant and have the same sign as before. ${ }^{19}$

As a further step to control for omitted variable bias, we include interactions of the trade and technology control variables with our green potential measure $\hat{\eta}_{i}$ in the model specification in column (3). This allows us to take into account the possibility of heterogeneous trade and technology shocks. What comes to mind are, e.g. the enlargement of the European Union or computerization as a technological trend. If such shocks have not only had an average effect on occupational employment (as modelled in column 2) but have also affected occupations similarly as has environmental policy, this would result in omitted variable bias. The two interactions control for this concern. In addition, we further include linear time trends that differ between macro-occupational groups (i.e. between ISCO 1-digit groups). Using such trends can control for underlying technological changes

\footnotetext{
${ }^{18}$ For the bottom-ranked occupation, we derive the employment response by calculating $\hat{\beta}_{1} \times 0.131=-0.236 \times$ $0.131=0.031$ or $3.1 \%$. Similarly, for the top-ranked occupation, we calculate $\hat{\beta}_{1} \times 0.131+\hat{\beta}_{2} \times 0.131=(-0.236 \times$ $0.131)+(0.391 \times 0.131)=0.020$ or $2.0 \%$.

${ }^{19}$ We perform additional sensitivity tests in the next section. For example, we focus on specific countries and sub-sample regressions to check for potentially omitted trends.
} 
that differently affect macro-occupational groups (e.g. "Professionals" vs. "Clerical support workers"). As one can see in column (3), including these new control variables does somewhat alter the regression estimates. Both coefficients on environmental policy slightly decrease in size but remain highly significant.

Regarding the employment response following an average EPS-change of 0.131, our full model specification in column (3) now estimates slightly different results: Occupational employment responses now range from a $1.8 \%$ decrease for the bottom-ranked occupation to a $2.6 \%$ increase for the top-ranked occupation. This means that after controlling for various confounding factors, we still find substantial heterogeneity between occupations.

What this suggests is that considering the heterogeneity of occupations in terms of their green potential provides a nuanced view on employment effects resulting from increased environmental policy stringency. This can best be demonstrated by looking at the coefficient on environmental policy in column (4). In this model specification, there is no heterogeneity between occupations. Rather, the model estimates an average effect across all occupations. Different to the previous estimation results, the estimated coefficient in column (4) is clearly non-significant. Moreover, the size of the coefficient is very small. This is because there is a relatively large number of occupations with rather low green potential and negligible employment responses. If we again consider the employment response of an average EPS-change by 0.131 , not taking into account any heterogeneity between occupations, our estimates from column (4) would imply a decrease of occupational employment by $-0.009 * 0.131=-0.001$ or $-0.1 \%$. However, because the coefficient in column (4) is not significantly different from zero, we cannot even exclude that occupational employment on average does not react at all. In general, this is in line with previous studies that have measured negligible or non-existent effects from environmental policy on employment (see e.g. Vona et al., 2018). But this view could be too narrow. As our empirical results in columns (1)-(3) highlight, there are occupations which could witness substantial employment gains or losses from increased environmental policy stringency.

However, this finding hinges on our green potential measure $\hat{\eta}_{i}$, which we have constructed from the data. Thus, $\hat{\eta}_{i}$ is an estimate of green potential and we want to test if we indeed capture important information with it. In order to test this, we have randomly assigned green potential values to all occupations and have then re-estimated our fully specified regression model (i.e. we have estimated a "placebo regression"). If green potential is indeed important and our measure captures it well, then the random assignment of $\hat{\eta}_{i}$ should make the regression coefficients nonsignificant. In our placebo regression, this is the case (estimation results can be found in Table 19 in the Appendix). The results from this test are reassuring that our green potential measure $\hat{\eta}_{i}$ does capture important information of occupations and is suitable for analyzing our research question.

So far, we have estimated several model specifications to address problems of omitted variable bias. As we pointed out in Section 3, another concern of our estimation strategy is reversed causality. We thus re-estimate our model using an instrumental variable approach. As described in Section 3, we use average foreign environmental policy stringency as an instrument for our potentially endogenous variable of domestic environmental policy stringency. We have argued that the 
Table 3: Instrument Relevance (Fixed Effects Estimation)

\begin{tabular}{|c|c|c|c|}
\hline & \multicolumn{3}{|c|}{ Dependent variable: } \\
\hline & \multicolumn{3}{|c|}{ Domestic Environmental Policy } \\
\hline & $(1)$ & $(2)$ & $(3)$ \\
\hline Foreign Environmental Policy & $\begin{array}{c}0.868^{* * *} \\
(0.128) \\
\end{array}$ & $\begin{array}{c}0.755^{* * *} \\
(0.151) \\
\end{array}$ & $\begin{array}{c}0.793^{* * *} \\
(0.164) \\
\end{array}$ \\
\hline Country fixed effects & $\checkmark$ & $\checkmark$ & $\checkmark$ \\
\hline Time trend & $\checkmark$ & $\checkmark$ & $\checkmark$ \\
\hline Business cycle, trade \& technology & & $\checkmark$ & $\checkmark$ \\
\hline Demographic \& sector controls & & & $\checkmark$ \\
\hline Weak instrument Wald test (F-Value) & 46.3 & 25.0 & 23.5 \\
\hline Observations & 324 & 324 & 311 \\
\hline $\mathrm{R}^{2}$ & 0.804 & 0.817 & 0.820 \\
\hline Adjusted $\mathrm{R}^{2}$ & 0.791 & 0.803 & 0.803 \\
\hline
\end{tabular}

Notes: The sample is an unbalanced panel that covers 19 European countries between 1992 and 2010. The dependent variable in all columns is the domestic environmental policy stringency index. All model specifications include fixed effects for 19 countries and a common linear time trend. Columns (2) and (3) also include a set of control variables. Business cycle, trade and technology controls consist of the national unemployment rate, the logged share of exports plus imports over GDP and the logged patent stock invented by domestic residents. Demographic and sector controls include the following: First, the ratio between the population share of the working age population (16-65 years old) to pensioners $(65+$ years old), then the female labor force participation rate as well as the log of the national population and the log of total manufacturing employment. Data is from the OECD and Eurostat. Standard errors are clustered at country-level (19 countries) and are robust against heteroskedasticity. Significance levels for the coefficients are indicated as: ${ }^{*} \mathrm{p}<0.1 ;{ }^{* *} \mathrm{p}<0.05 ;{ }^{* * *} \mathrm{p}<0.01$

exclusion restriction holds if average foreign environmental policy stringency only affects domestic employment patterns through domestic environmental policy stringency. This assumption cannot be tested empirically. In turn, what can be investigated is the relevance of our instrument. If an instrument is not a relevant instrument, it is considered a "weak instrument", which leads to biased estimates (see, for example, Bound et al., 1995). As a rule of thumb, a relevant instrument should have an F-value above 10 in the first stage, i.e. it should explain an important part of the variation in the potentially endogenous variable. In our case, this means that average foreign environmental policy stringency should appropriately explain domestic environmental policy stringency. We test this with different model specifications for the relationship between the two variables in Table 3 . As specified in Equations (3) and (4), environmental policy stringency is measured on the country level and, therefore, the relationship between foreign and domestic policy stringency is now also estimated on the country level. It is reassuring that weak instruments tests show F-values that are much larger than 10 in all the different model specifications shown in Table 3. This indicates that we can reject the hypothesis that foreign environmental policy stringency is only a weak instrument 
for domestic environmental policy stringency. ${ }^{20}$

In what follows, we proceed with our IV-approach and re-estimate the model specifications from Table 2 using average foreign environmental policy stringency as an instrument for domestic environmental policy stringency. The corresponding results are presented in Table 4. As before, the coefficients imply substantial heterogeneity with respect to the green potential of occupations. In column (1)-(3) of Table 4, both the coefficients on the bottom- and the top-ranked occupation are highly significant and of larger size than before. This indicates that our previous fixed effects estimates could have been biased by reverse causality. One potential mechanism explaining this could be political lobbying. Take, for example, occupational groups, who are relatively likely to suffer from more stringent regulations. If they anticipate this negative effect, they will lobby against too stringent environmental policies. This, in turn, would result in weaker regulations and thereby cause reverse causality in a fixed effects model framework. The IV-approach is robust against such sources of bias, and we will thus use the results from this approach in the remainder of this paper. ${ }^{21}$

As in the previous fixed effects estimation, the coefficient on the bottom-ranked occupation from the IV model decreases in column (2). In this specification, the model controls for countryspecific general economic conditions (i.e. the business cycle, trade and technological trends) and sectoral as well as demographic trends. This suggests that controlling for country-specific trends is still important when using an IV approach. The coefficient on the top-ranked occupation (i.e. the coefficient on the interaction term), in turn, remains more or less unaffected by the inclusion of these control variables. Going one step further to column (3), both coefficients now remain very stable and do not seem to be overly sensitive to including ISCO 1-digit trends and interaction terms.

In the baseline model specification presented in column (3), the estimated employment change associated with an increase in environmental policy stringency by 0.131 on the bottom-ranked occupation is now $-0.189 * 0.131=-0.025$, i.e. an employment decrease of $2.5 \%$. On the other hand, employment is expected to increase by $-0.189 * 0.131+0.462 * 0.131=-0.036$ or $-3.6 \%$ for the top-ranked occupation. Our IV regression therefore suggests even stronger heterogeneous labor demand responses from environmental policy changes. As before, we also report an estimate for the average effect across all occupations in column (4). In contrast to the specifications in columns (1)-(3), where heterogeneity between occupations is modelled, the size and significance level of the coefficient on environmental policy stringency in column (4) is practically identical to the previous fixed effects model results. In particular, the coefficient is non-significant. The implied average employment response resulting from an EPS-change by 0.131 is $0.131 *(-0.010)=0.001$, which

\footnotetext{
${ }^{20}$ In addition, Table 15 in the Appendix provides a robustness check to the exogeneity assumption of our instrument. As we have argued, the instrument would not be valid if, for example, domestic employment patterns influence multilateral negotiations on environmental issues, which, in turn, affect average foreign environmental policy. Clearly, this threat to the validity of our instrument is more relevant for larger and politically more powerful countries. We thus exclude the G7 member countries of Germany, France, Italy and the United Kingdom from our sample and re-estimate the model from Table 3. It is reassuring that the estimation results from this sub-sample do not change substantially, which indicates that our instruments should be robust against the above-mentioned validity concerns.

${ }^{21}$ Following the rationale outlined in Footnote 20, we have also estimated all regression specifications from Table 4 without including G7 member countries. As for the first stage, the estimates from this sub-sample regression remain practically unchanged (see Table 17 in the Appendix).
} 
Table 4: Impact of Environmental Policy Stringency on Employment (IV Fixed Effects)

\begin{tabular}{|c|c|c|c|c|}
\hline & & Dependen & ariable: & \\
\hline & & $\log ($ emplo & $\left.\operatorname{nent}_{i_{j t}}\right)$ & \\
\hline & $(1)$ & $(2)$ & $(3)$ & $(4)$ \\
\hline Environmental Policy $_{j, t-1}$ & $\begin{array}{c}-0.292^{* * *} \\
(0.033)\end{array}$ & $\begin{array}{c}-0.179^{* * *} \\
(0.030)\end{array}$ & $\begin{array}{c}-0.189^{* * *} \\
(0.039)\end{array}$ & $\begin{array}{l}-0.010 \\
(0.015)\end{array}$ \\
\hline $\begin{array}{l}\text { Environmental Policy }{ }_{j, t-1} \times \\
\text { Green Potential } \hat{\eta}_{i}\end{array}$ & $\begin{array}{c}0.460^{* * *} \\
(0.069)\end{array}$ & $\begin{array}{c}0.438^{* * *} \\
(0.067)\end{array}$ & $\begin{array}{c}0.462^{* * *} \\
(0.093)\end{array}$ & \\
\hline Occupation-country fixed effects & $\checkmark$ & $\checkmark$ & $\checkmark$ & $\checkmark$ \\
\hline Year dummies & & $\checkmark$ & $\checkmark$ & $\checkmark$ \\
\hline Country time trends & & $\checkmark$ & $\checkmark$ & $\checkmark$ \\
\hline Business cycle, trade \& technology & & $\checkmark$ & $\checkmark$ & $\checkmark$ \\
\hline Demographic \& sector controls & & $\checkmark$ & $\checkmark$ & $\checkmark$ \\
\hline Trade \& technology interactions & & & $\checkmark$ & $\checkmark$ \\
\hline 1-digit ISCO time trends & & & $\checkmark$ & $\checkmark$ \\
\hline Observations & 11,543 & 11,123 & 11,123 & 11,123 \\
\hline $\mathrm{R}^{2}$ & 0.045 & 0.071 & 0.112 & 0.105 \\
\hline Adjusted $\mathrm{R}^{2}$ & -0.018 & 0.006 & 0.049 & 0.041 \\
\hline
\end{tabular}

Notes: The sample is an unbalanced panel that covers 19 European countries between 1992 and 2010. The dependent variable in all columns is the log of occupational employment. All model specifications include fixed effects for country-specific occupations. Columns (2) to (4) further include year dummies, country-specific linear time trends and a set of control variables. More specifically, columns (2) to (4) include the national unemployment rate, the logged share of exports plus imports over GDP and the logged patent stock invented by domestic residents to control for the business cycle as well as trends in trade and technology. Demographic and sector controls consist of the following variables: The working age (16-64 years old) to pension age (65 years and older) ratio, the female labor force participation rate, the $\log$ of the total population and the log of total manufacturing employment. In columns (3) and (4) the trade and technology control variables from column (2) are additionally interacted with the green potential measure $\hat{\eta}_{i}$, thereby constructing two new controls on the occupation level. Moreover, columns (3) and (4) incorporate a linear time trend on the 1-digit ISCO level. Data is from the OECD and Eurostat. Standard errors in parentheses are clustered at the level of country-specific occupations (721 country-specific ISCO 3-digit occupations) and are robust against heteroskedasticity. Significance levels for the coefficients are indicated as: ${ }^{*} \mathrm{p}<0.1 ;{ }^{* *} \mathrm{p}<0.05 ;{ }^{* * *} \mathrm{p}<0.01$

corresponds to a decrease of employment by $0.1 \%$ and can be considered non-existent.

So far, we have investigated the relationship between environmental policy stringency and employment. Our empirical findings suggest substantial heterogeneity between occupations and, accordingly, there will be winners and losers from increased environmental policy stringency. In the next subsections, we will examine the sensitivity of this finding and illustrate employment responses following an environmental policy shock at the aggregate level.

\section{Sensitivity Analysis}

We start with a robustness check that additionally controls for omitted variable bias resulting from globalization and technological trends. We consider these trends to be the most relevant 
potential confounders for our baseline estimates. ${ }^{22}$ In our baseline IV regression, we have included several control variables for the purpose of taking into account such structural trends. Thus, we expect our baseline IV-model specification to substantially reduce threats of omitted variable bias. However, despite the inclusion of these control variables, some concerns remain. If, for example, all of our control variables do not adequately capture actual globalization and technological trends, our estimates could still be biased. The same could occur if the EPS index is highly correlated with globalization and technological trends. Thus, we want to test our findings against this potential threat to the validity of our results.

In order to do so, we split our sample into groups of occupations that should be similarly affected by technological trends and globalization, respectively. Because of the similarity, there should no longer be substantial heterogeneity resulting from technology or globalization trends within these occupational groups. In our regression model, the coefficient $\beta_{2}$ in Equation (3) (i.e. the coefficient on the top-ranked occupation) captures heterogeneity between occupations. Thus, if our baseline results suffer from omitted variable bias, this coefficient should become smaller and non-significant when separately estimating the model for the different groups. Stated differently, if such regressions lead to similar coefficients compared to our baseline estimates, our results can be considered relatively robust against omitted variable bias from globalization and technological trends.

The first step of this robustness check is to determine groups of similar occupations. In order to do so, we follow Goos et al. (2014), who provide information on the routine task intensity and offshorability of 2-digit ISCO occupations. ${ }^{23}$ Ordering occupations along these two characteristics allows us to construct occupational groups for each measure. We construct three groups, each consisting of 6 or 7 2-digit ISCO occupations with "high", "middle" and "low" exposure to technological trends and offshoring, respectively. ${ }^{24}$ We then run our baseline IV model on the three groups separately. As argued before, if our previous results were driven by omitted variable bias, we should no longer see substantial heterogeneity within these groups. In turn, if we still observe heterogeneous employment responses from environmental policy stringency, this would suggest that our findings are indeed primarily driven by environmental policy stringency. Note, however, that it is impossible to construct perfectly homogeneous groups with regard to technology and globalization. As a result, the heterogeneity (and its corresponding regression coefficient) would not vanish completely (i.e. become zero), even if the baseline estimates were entirely driven by omitted variables. Nevertheless, the regression coefficient capturing heterogeneity should still strongly decrease in this case. The regression results for each group are presented in Table 5. Columns (1)

\footnotetext{
${ }^{22}$ This is motivated by Marin and Vona (2019) and extensive literature which suggests that routine biased technical change and globalization have both affected occupations heterogeneously. Some important contributions are Goos et al. (2014) Autor and Dorn (2013), Autor et al. (2013) and, more recently, Gregory et al. (2018).

${ }^{23}$ More specifically, Goos et al. (2014) use the routine task intensity index (RTI) developed by Autor and Dorn (2013) as a measure of exposure to technological trends and the offshorability index from Blinder and Krueger (2013) for exposure to globalization. They transfer these measures to 2-digit ISCO occupations. The data is available in the online Appendix from Goos et al. (2014).

${ }^{24} \mathrm{As}$ occupations in our analysis are on the 3-digit ISCO level, we assign them to the routine task intensity and offshorability groups of their respective 2-digit ISCO groups. For example, the 3-digit ISCO occupation, "122 Production and operations managers", belongs to the 2-digit ISCO group " 12 Corporate managers". This particular 2-digit group has a low routine task intensity in Goos et al. (2014) and we have thus classified it to the "low RTI" group. Accordingly, "122 Production and operations managers" are also assigned to this class of occupations.
} 
to (3) present the estimates for the three groups and column (4) shows the IV-estimates from our baseline model.

Table 5: Environmental Policy, Routine Task Intensity and Offshorability (IV Fixed Effects)

\begin{tabular}{|c|c|c|c|c|}
\hline & $\begin{array}{c}(1) \\
\text { high RTI }\end{array}$ & $\begin{array}{c}(2) \\
\text { middle RTI }\end{array}$ & $\begin{array}{c}(3) \\
\text { low RTI }\end{array}$ & $\begin{array}{c}(4) \\
\text { baseline }\end{array}$ \\
\hline Environmental Policy $j, t-1$ & $\begin{array}{c}-0.179^{* * *} \\
(0.050)\end{array}$ & $\begin{array}{c}-0.192^{* *} \\
(0.086)\end{array}$ & $\begin{array}{c}-0.196^{* *} \\
(0.087)\end{array}$ & $\begin{array}{c}-0.189^{* * *} \\
(0.039)\end{array}$ \\
\hline Environmental Policy $_{j, t-1} \times$ & $0.559^{* * *}$ & $0.401^{* *}$ & $0.349^{* * *}$ & $0.462^{* * *}$ \\
\hline Green Potential $\hat{\eta}_{i}$ & $(0.144)$ & $(0.189)$ & $(0.136)$ & $(0.093)$ \\
\hline Observations & 5,831 & 3,263 & 1,993 & 11,123 \\
\hline $\mathrm{R}^{2}$ & 0.120 & 0.076 & 0.174 & 0.112 \\
\hline \multirow[t]{2}{*}{ Adjusted $\mathrm{R}^{2}$} & 0.054 & 0.000 & 0.097 & 0.049 \\
\hline & $\begin{array}{c}(1) \\
\text { high } \\
\text { offshorability }\end{array}$ & $\begin{array}{c}(2) \\
\text { middle } \\
\text { offshorability }\end{array}$ & $\begin{array}{c}(3) \\
\text { low } \\
\text { offshorability }\end{array}$ & $\begin{array}{c}(4) \\
\text { baseline }\end{array}$ \\
\hline Environmental Policy ${ }_{j, t-1}$ & $\begin{array}{c}-0.136^{* * *} \\
(0.045)\end{array}$ & $\begin{array}{l}-0.037 \\
(0.086)\end{array}$ & $\begin{array}{c}-0.282^{* * *} \\
(0.103)\end{array}$ & $\begin{array}{c}-0.189^{* * *} \\
(0.039)\end{array}$ \\
\hline Environmental Policy $_{j, t-1} \times$ & $0.415^{* * *}$ & 0.025 & $0.602^{* * *}$ & $0.462^{* * *}$ \\
\hline Green Potential $\hat{\eta}_{i}$ & $(0.119)$ & $(0.185)$ & $(0.222)$ & $(0.093)$ \\
\hline Observations & 5,757 & 3,348 & 1,982 & 11,123 \\
\hline & 0.169 & 0.123 & 0.113 & 0.112 \\
\hline Adjusted $\mathrm{R}^{2}$ & 0.106 & 0.051 & 0.029 & 0.049 \\
\hline Country fixed effects & $\checkmark$ & $\checkmark$ & $\checkmark$ & $\checkmark$ \\
\hline Year dummies & $\checkmark$ & $\checkmark$ & $\checkmark$ & $\checkmark$ \\
\hline Country time trends & $\checkmark$ & $\checkmark$ & $\checkmark$ & $\checkmark$ \\
\hline Business cycle, trade \& technology & $\checkmark$ & $\checkmark$ & $\checkmark$ & $\checkmark$ \\
\hline Demographic \& sector controls & $\checkmark$ & $\checkmark$ & $\checkmark$ & $\checkmark$ \\
\hline Trade \& technology interactions & $\checkmark$ & $\checkmark$ & $\checkmark$ & $\checkmark$ \\
\hline 1-digit ISCO time trends & $\checkmark$ & $\checkmark$ & $\checkmark$ & $\checkmark$ \\
\hline
\end{tabular}

Notes: The sample is an unbalanced panel that covers 19 European countries between 1992 and 2010. The dependent variable in all columns is the log of occupational employment. The regression model in all columns includes fixed effects for country-specific occupations, year dummies, country-specific linear time trends and a set of control variables. More specifically, the national unemployment rate, the logged share of exports plus imports over GDP and the logged patent stock invented by domestic residents control for the business cycle as well as trends in trade and technology. Demographic and sector controls consist of the following variables: The working age (16-64 years old) to pension age (65 years and older) ratio, the female labor force participation rate, the log of the total population and the log of total manufacturing employment. Moreover, the trade and technology control variables are additionally interacted with the green potential measure $\hat{\eta}_{i}$, which provides two additional control variables on the occupation level. Lastly, the model incorporates a linear time trend on the 1-digit ISCO level. Data is from the OECD and Eurostat. Standard errors in parentheses are clustered at the level of country-specific occupations and are robust against heteroskedasticity. Significance levels for the coefficients are indicated as: ${ }^{*} \mathrm{p}<0.1 ;{ }^{* *} \mathrm{p}<0.05$; ${ }^{* * *} \mathrm{p}<0.01$

Our previous findings should be robust against omitted variable bias resulting from trade or technology if the coefficient of the term $\left\{\right.$ Environmental policy $t_{t-1} \times$ green potential $\}$ does not 
substantially change in the subgroup regressions. In our baseline IV-regression, this coefficient was 0.462 . We first compare this estimate with the three RTI groups in the upper half of Table 5 . Interestingly, the coefficient increases in size for the high RTI group in column (1). One explanation for this is the occupational composition of the high-RTI group. In Goos et al. (2014), occupations with high RTI are either technical or administrative jobs. In our estimates of the green potential of occupations, however, we have observed that technical occupations have rather high green potential and administrative occupations are ranked at lower positions of the distribution. Thus, this group features a wide range of occupations in terms of green potential. And what follows from this is that the heterogeneity increases compared to the full sample estimates. In turn, the coefficient decreases for the middle and low RTI groups in columns (2) and (3). However, the decrease is not very large and the coefficient remains positive and highly significant in all subgroup regressions.

In the lower half of Table 5, we repeat the procedure for the offshorability groups. Column (1) presents results for occupations that are highly offshorable. For this group, we observe declining heterogeneity, which is different compared to the RTI case. However, the decrease of the coefficients is very small and we consider it negligible compared to the baseline estimate in column (4). In column (2), in turn, the heterogeneity decreases drastically. The coefficient on the interaction term of our model decreases from 0.462 in the baseline model to only 0.025 in column (2). Further, it becomes clearly non-significant and, at the same time, the coefficient on environmental policy without the interaction also becomes very small and non-significant. This indicates that occupations from this group seem to be unaffected by environmental policy in general. Accordingly, there is also no heterogeneity. In other words, the lack of occupational heterogeneity within the middle offshorable group of occupations seems to stem from the fact that in this group many occupations are unaffected by environmental policy. However, this finding is specific to the middle offshorability group. For the low offshorable group presented in column (3), we again observe a similar pattern as we did for the high-RTI class. The heterogeneity in this group even increases compared to the baseline estimates.

In sum, in five of our six sub-group regressions, we observe results which suggest that our baseline estimates are not biased by omitted variables. ${ }^{25}$ Therefore, we conclude that our findings are not driven solely by technological trends or globalization.

Next, we turn to a somewhat related cause of concern, which is that our findings could be primarily driven by a very specific sub-period. To investigate this, we split our sample into three sub-samples, each consisting of six or seven years. The first sub-sample ranges from 1992-1998 (we assign 7 years to this period because it has the lowest number of observations), the second from 1999-2004 and the last one from 2005-2010. Note that the evolution of the EPS index differs among these three sub-periods (see Figure 1) and, accordingly, we expect to find different parameter estimates when we run the baseline IV-regressions on the three sub-samples. The results are presented in columns (1) to (3) of Table 6 and in column (4), we again report the baseline IV-estimates. Compared to the baseline regression, the results from the sub-periods 2005-2010

\footnotetext{
${ }^{25}$ Table 20 in the Appendix presents further evidence for this argument. It shows estimates of our baseline regression model using the RTI and offshorability measures as control variables for technological changes and offshoring trends at the level of occupations. It is reassuring that our baseline estimates also remain robust against this alternative regression specification.
} 
and 1999-2004 in columns (1) and (2) are relatively similar, especially for the bottom-ranked occupations. In fact, the coefficient on the bottom-ranked occupation is larger than in the baseline regression, which suggests that later years of our sample are mainly driving the baseline results. In contrast, the estimated coefficients for the sub-period 1992-1998 presented in column (3) decrease in size and the relationship breaks down since the coefficients' standard errors become very large. Note, however, that over these years, the EPS index hardly moved at all. Thus, we would also expect no occupational employment responses. Therefore, it is reassuring to find no significant employment responses when the EPS index did not change substantially. In summary, we find evidence that the estimated relationship from the baseline IV-regression does not stem from an unobserved general trend. Moreover, the relationship is mainly driven by later periods in our sample.

Table 6: Impact of Environmental Policy: Sub-periods (IV Fixed Effects)

\begin{tabular}{lcccc}
\hline \hline & $(1)$ & $(2)$ & $(3)$ & $(4)$ \\
& $2005-2010$ & $1999-2004$ & $1992-1998$ & full sample \\
\hline Environmental Policy ${ }_{j, t-1}$ & $-0.219^{* * *}$ & $-0.204^{* *}$ & -0.136 & $-0.189^{* * *}$ \\
& $(0.040)$ & $(0.082)$ & $(0.345)$ & $(0.039)$ \\
Environmental Policy ${ }_{j, t-1} \times$ & $0.330^{* * *}$ & $0.482^{* *}$ & 0.379 & $0.462^{* * *}$ \\
Green Potential $\hat{\eta}_{i}$ & $(0.088)$ & $(0.193)$ & $(0.903)$ & $(0.093)$ \\
\hline Country fixed effects & $\checkmark$ & $\checkmark$ & $\checkmark$ & $\checkmark$ \\
Country time trends & $\checkmark$ & $\checkmark$ & $\checkmark$ & $\checkmark$ \\
Year dummies & $\checkmark$ & $\checkmark$ & $\checkmark$ & $\checkmark$ \\
Business cycle, trade \& technology & $\checkmark$ & $\checkmark$ & $\checkmark$ & $\checkmark$ \\
Demographic \& sector controls & $\checkmark$ & $\checkmark$ & $\checkmark$ & $\checkmark$ \\
Trade \& technology interactions & $\checkmark$ & $\checkmark$ & $\checkmark$ & $\checkmark$ \\
1-digit ISCO time trends & $\checkmark$ & $\checkmark$ & $\checkmark$ & $\checkmark$ \\
Observations & & & & $\checkmark$ \\
$\mathrm{R}^{2}$ & 4,116 & 4,115 & 2,892 & 11,123 \\
Adjusted R & & & $\checkmark$ & \\
\hline \hline
\end{tabular}

Notes: The sample is an unbalanced panel that covers 19 European countries between 1992 and 2010. The dependent variable in all columns is the log of occupational employment. The regression model in all columns includes fixed effects for country-specific occupations, year dummies, country-specific linear time trends and a set of control variables. More specifically, the national unemployment rate, the logged share of exports plus imports over GDP and the logged patent stock invented by domestic residents control for the business cycle as well as trends in trade and technology. Demographic and sector controls consist of the following variables: The working age (16-64 years old) to pension age (65 years and older) ratio, the female labor force participation rate, the log of the total population and the log of total manufacturing employment. Moreover, the trade and technology control variables are additionally interacted with the green potential measure $\hat{\eta}_{i}$, which provides two additional control variables on the occupation level. Lastly, the model incorporates a linear time trend on the 1-digit ISCO level. Data is from the OECD and Eurostat. Standard errors in parentheses are clustered at the level of country-specific occupations and are robust against heteroskedasticity. Significance levels for the coefficients are indicated as: ${ }^{*} \mathrm{p}<0.1 ;{ }^{* *} \mathrm{p}<0.05 ;{ }^{* * *} \mathrm{p}<0.01$

Thus far, we have investigated two different sources of bias, which could arise from our model specification. Next, we turn to examining if the baseline IV-results could have been driven by large outliers in our sample. In order to test this, we again re-estimate our baseline IV-model from column (3) in Table 4. But now we exclude those observations from our sample for which the main 
explanatory variable lies within the top $0.5 \%$ (i.e. the interaction of environmental policy $E P S_{j, t}$ and green potential $\hat{\eta}_{i}$ ). The results from estimating the model with this outlier-corrected sample are presented in column (1) of Table 7. The sample size is reduced to 11,045 observations but the coefficients remain very stable for the bottom-ranked occupation and increase slightly in size for the top-ranked occupation. Additionally, both coefficients are again highly significant, which indicates that our previous results were not driven solely by some outliers.

Table 7: Impact of Environmental Policy: Excluding Potential Outliers (IV Fixed Effects)

\begin{tabular}{lcccc}
\hline \hline & $(1)$ & $(2)$ & $(3)$ & $(4)$ \\
& $\begin{array}{c}\text { exclude Top } \\
\text { exclude CZ, } \\
\text { SK, HU }\end{array}$ & $\begin{array}{c}\text { exclude GIIPS } \\
\text { countries }\end{array}$ & $\begin{array}{c}\text { exclude Great } \\
\text { Recession }\end{array}$ \\
\hline Environmental Policy ${ }_{j, t-1}$ & $-0.209^{* * *}$ & $-0.199^{* * *}$ & $-0.139^{* * *}$ & $-0.185^{* * *}$ \\
& $(0.041)$ & $(0.042)$ & $(0.039)$ & $(0.038)$ \\
Environmental Policy ${ }_{j, t-1}$ & $0.525^{* * *}$ & $0.472^{* * *}$ & $0.329^{* * *}$ & $0.426^{* * *}$ \\
Green Potential $\hat{\eta}_{i}$ & $(0.102)$ & $(0.103)$ & $(0.087)$ & $(0.093)$ \\
\hline Occupation-country fixed effects & $\checkmark$ & $\checkmark$ & $\checkmark$ & $\checkmark$ \\
Year dummies & $\checkmark$ & $\checkmark$ & $\checkmark$ & $\checkmark$ \\
Country time trends & $\checkmark$ & $\checkmark$ & $\checkmark$ & $\checkmark$ \\
Business cycle, trade \& technology & $\checkmark$ & $\checkmark$ & $\checkmark$ & $\checkmark$ \\
Demographic \& sector controls & $\checkmark$ & $\checkmark$ & $\checkmark$ & $\checkmark$ \\
Trade \& technology interactions & $\checkmark$ & $\checkmark$ & $\checkmark$ & $\checkmark$ \\
1-digit ISCO time trends & $\checkmark$ & $\checkmark$ & $\checkmark$ & 9,751 \\
Observations & 11,045 & 9,721 & 7,304 & 0.120 \\
$\mathrm{R}^{2}$ & 0.113 & 0.118 & 0.088 & 0.049 \\
Adjusted R $\mathrm{R}^{2}$ & 0.049 & 0.057 & 0.019 & $\checkmark$ \\
\hline \hline
\end{tabular}

Notes: The sample is an unbalanced panel that covers 19 European countries between 1992 and 2010. The dependent variable in all columns is the log of occupational employment. The regression model in all columns includes fixed effects for country-specific occupations, year dummies, country-specific linear time trends and a set of control variables. More specifically, the national unemployment rate, the logged share of exports plus imports over GDP and the logged patent stock invented by domestic residents control for the business cycle as well as trends in trade and technology. Demographic and sector controls consist of the following variables: The working age (16-64 years old) to pension age (65 years and older) ratio, the female labor force participation rate, the log of the total population and the log of total manufacturing employment. Moreover, the trade and technology control variables are additionally interacted with the green potential measure $\hat{\eta}_{i}$, which provides two additional control variables on the occupation level. Lastly, the model incorporates a linear time trend on the 1-digit ISCO level. Data is from the OECD and Eurostat. Standard errors in parentheses are clustered at the level of country-specific occupations and are robust against heteroskedasticity. Significance levels for the coefficients are indicated as: ${ }^{*} \mathrm{p}<0.1 ;{ }^{* *} \mathrm{p}<0.05 ;{ }^{* *} \mathrm{p}<0.01$

In columns (2)-(4) of Table 7, we focus on the robustness of our estimates against excluding specific countries and years from the sample. The motivation for this is that there are some countries that have witnessed important structural changes during this period. This is especially the case for the Eastern European countries of Hungary, Slovakia and the Czech Republic, who joined the European Union (EU) in 2004. In the process of their EU accession, these countries have implemented a wide range of new policies. Moreover, these three countries started with rather low initial EPS levels and have since experienced the most substantial average increases in environmental policy stringency over the sample period (see Figure 2). If, however, general legal and institutional changes in these countries were the actual drivers of heterogeneous employment changes, our re- 
sults could be biased. Therefore, we re-estimate our baseline IV-model once more, but we exclude Hungary, Slovakia and the Czech republic from the sample. Column (2) of Table 7 presents the results. We observe a similar trend as in our previous robustness checks: The coefficients on both the top- and bottom-ranked occupations remain highly significant. For the bottom-ranked occupation, the coefficient remains very stable, while the coefficient for the top-ranked occupation has increased slightly. This somehow confirms that our estimates are not driven by structural changes induced on Eastern European countries by their EU accession. A similar bias could have occurred as a result of the introduction of the Euro in 2002. Especially in Greece, Italy, Ireland, Portugal and Spain - the so-called GIIPS countries - this has led to significant macroeconomic adjustment processes (e.g. Lane, 2012; Eichengreen, 2010). In our baseline regression in column (3) of Table 4 we control for this potential bias by including year dummies, general economic trends, as well as country-level linear time trends. If, however, such trends resulting from the introduction of the Euro have had heterogeneous effects on occupational labor demand, our results could be driven by the GIIPS countries only. Thus, we exclude these countries from our sample and re-estimate our model. This drastically reduces the sample size to 7,304 observations and changes the size of the coefficients. Nevertheless, both coefficients remain highly significant, their sign is unchanged and the $90 \%$ confidence intervals overlap with our baseline IV results. Thus, we rule out that the introduction of the Euro and its induced structural change in some specific countries are driving our previous results.

Lastly, we evaluate the sensitivity of our results against excluding the years of the so-called Great Recession in 2008 and 2009. The common shock to occupational demand, which occurred in response to the global financial crisis, is controlled for by year dummies in our baseline estimation. However, the shock from the Great Recession has likely been heterogeneous between countries and occupations and could be insufficiently captured by the country-level time trends included in our models. Thus, we exclude the years 2008 and 2009 from our sample and re-estimate the baseline model in column (4). The results from this estimation remain practically identical to the baseline estimates presented in column (3) of Table 4. This indicates that a potentially heterogeneous impact of the Great Recession is captured well in our baseline IV model. To summarize, the results from Table 7 suggest that the observed relationship between environmental regulation and employment remains stable if potential outliers, specific countries or years are excluded from the sample. These findings indicate that our baseline IV estimates are unbiased with respect to potential outliers and are not driven by structural shocks in specific countries.

As a last check to the sensitivity of our baseline IV estimates, we examine potential measurement error in our main explanatory variable. Our explanatory variable of interest is the country-level EPS index developed by the OECD. It is a composite indicator, constructed as the average of a broad range of policies and is aggregated at the country level. Thus, it is possible that it is driven by specific policies that might not matter for our analysis to some extent. We examine this with a robustness tests using sub-indicators of the overall EPS index as explanatory variables. ${ }^{26}$ Indeed, the regression coefficients vary to some extent depending on the chosen policy index. Overall, however, the same pattern of occupational heterogeneity as in our baseline findings

\footnotetext{
${ }^{26}$ We do this for the EPS sub-indicators 'market-based policies', 'non-market policies', 'taxes', 'trading schemes' and 'standards'. For more information see Botta and Koźluk (2014).
} 
emerges. This is reassuring and suggests that our findings are robust against the choice of different EPS sub-indicators. All corresponding IV regression estimates are provided in Table 22 in the Appendix.

To further control for measurement error in our baseline regression's explanatory variable, we also re-estimate our model from Equation (3) using an alternative measure of environmental policy stringency compared to the EPS index and its sub-indicators. Instead, we calculate the amount of total expenditure on pollution taxes (in USD) per ton of pollution in $\mathrm{CO}_{2}$ equivalents. The data for this measure is obtained from Eurostat and it can be interpreted as an approximation of a county-level implicit pollution tax. As before, we instrument the domestic implicit pollution tax with the average foreign implicit pollution tax to account for potential simultaneity. Regression results using this measure as the explanatory variable of interest are presented in Table 8.

Table 8: Impact of the Implicit Pollution Tax on Employment (IV Fixed Effects)

\begin{tabular}{|c|c|c|c|c|}
\hline & \multicolumn{4}{|c|}{ Dependent variable: } \\
\hline & \multicolumn{4}{|c|}{$\log \left(\right.$ employment $\left._{i_{j t}}\right)$} \\
\hline & $(1)$ & $(2)$ & $(3)$ & $(4)$ \\
\hline Implicit Pollution $\operatorname{Tax}_{j, t-1}$ & $\begin{array}{c}-0.050^{* * *} \\
(0.009)\end{array}$ & $\begin{array}{c}-0.032^{* * *} \\
(0.008)\end{array}$ & $\begin{array}{c}-0.041^{*} \\
(0.023)\end{array}$ & $\begin{array}{c}-0.008^{* *} \\
(0.004)\end{array}$ \\
\hline $\begin{array}{l}\text { Implicit Pollution } \operatorname{Tax}_{j, t-1} \times \\
\text { Green Potential } \hat{\eta}_{i}\end{array}$ & $\begin{array}{c}0.062^{* * *} \\
(0.019)\end{array}$ & $\begin{array}{c}0.062^{* * *} \\
(0.019)\end{array}$ & $\begin{array}{c}0.085 \\
(0.057) \\
\end{array}$ & \\
\hline Occupation-country fixed effects & $\checkmark$ & $\checkmark$ & $\checkmark$ & $\checkmark$ \\
\hline Year dummies & & $\checkmark$ & $\checkmark$ & $\checkmark$ \\
\hline Country time trends & & $\checkmark$ & $\checkmark$ & $\checkmark$ \\
\hline Business cycle, trade \& technology & & $\checkmark$ & $\checkmark$ & $\checkmark$ \\
\hline Demographic \& sector controls & & $\checkmark$ & $\checkmark$ & $\checkmark$ \\
\hline Trade \& technology interactions & & & $\checkmark$ & $\checkmark$ \\
\hline 1-digit ISCO time trends & & & $\checkmark$ & $\checkmark$ \\
\hline Observations & 4,250 & 4,180 & 4,180 & 4,180 \\
\hline $\mathrm{R}^{2}$ & 0.084 & 0.102 & 0.117 & 0.125 \\
\hline Adjusted $\mathrm{R}^{2}$ & -0.103 & -0.087 & -0.072 & -0.061 \\
\hline
\end{tabular}

Notes: The sample is an unbalanced panel that covers 19 European countries between 1992 and 2010. The dependent variable in all columns is the log of occupational employment. All model specifications include fixed effects for country-specific occupations. Columns (2) to (4) further include year dummies, country-specific linear time trends and a set of control variables. More specifically, columns (2) to (4) include the national unemployment rate, the logged share of exports plus imports over GDP and the logged patent stock invented by domestic residents to control for the business cycle as well as trends in trade and technology. Demographic and sector controls consist of the following variables: The working age (16-64 years old) to pension age (65 years and older) ratio, the female labor force participation rate, the log of the total population and the log of total manufacturing employment. In columns (3) and (4) the trade and technology control variables from column (2) are additionally interacted with the green potential measure $\hat{\eta}_{i}$, thereby constructing two new controls on the occupation level. Moreover, columns (3) and (4) incorporate a linear time trend on the 1-digit ISCO level. Data is from the OECD and Eurostat. Standard errors in parentheses are clustered at the level of country-specific occupations (721 country-specific ISCO 3-digit occupations) and are robust against heteroskedasticity. Significance levels for the coefficients are indicated as: ${ }^{*} \mathrm{p}<0.1{ }^{* *} \mathrm{p}<0.05 ;{ }^{* * *} \mathrm{p}<0.01$

The coefficients show the estimated change of occupational employment for the bottom- and 
top-ranked green potential occupation following a $1 \$$ increase in the implicit pollution tax. ${ }^{27}$ Due to limited availability of data for pollution in $\mathrm{CO}_{2}$ equivalents, our estimation sample shrinks to 4, 250 observations in column (1). Nevertheless, both coefficients on the top- and bottom-ranked green potential occupation are again highly significant and have the same direction as our IV results using the EPS index. This is also the case when we add control variables to reduce threats of omitted variable bias in column (2). In column (3) we incorporate further covariates in the model, which control for occupation-specific effects from trade and technological trends. This does not substantially alter the size of the coefficients, but yields standard errors approximately three times larger compared to column (2). Although the coefficients in column (3) still have the same direction compared to our baseline IV regression, the coefficient on the top-ranked green potential occupation now becomes non-significant. The coefficient on the bottom-ranked green potential occupation, in turn, remains significant on the $90 \%$ confidence level. In column (4), we also report the regression result if we do not take the heterogeneity of occupations into account. That is, we measure the average change in employment across occupations that is associated with an increase in the implicit pollution tax. In this case, the coefficient on environmental policy has the same direction compared to the baseline IV regression and is significant on the $90 \%$ confidence level. Also, it is much smaller compared to the coefficient estimate in column (3). This is reassuring because it implies that although the coefficient on the interaction term in column (3) is not significant, the coefficient on the bottom-ranked occupation does not correspond to the average effect. That is, heterogeneity is also present in the model specification of column (3), but cannot be estimated precisely enough. In fact, the p-value of the coefficient on the top-ranked occupation is 0.137 , which is close to significance on the $10 \%$ confidence level. In sum, using an alternative measure for environmental policy stringency rather than the EPS index results in the same empirical relationship between environmental policy and occupational employment.

\section{Implications of a Policy Shock}

Having investigated the robustness of our findings, we now use our empirical results to illustrate the implications of a specific environmental policy shock. Recall our baseline estimates from Table 4: Following an average change of environmental policy stringency by 0.131 , our model would predict an associated decrease of occupational employment by $2.5 \%$ for the bottom-ranked green potential occupation, and an increase of $3.6 \%$ for the top-ranked green potential occupation. Since the main contribution of our analysis is to provide insight on heterogeneous labor market responses, we next examine employment changes over the full distribution of manufacturing occupations. For an arbitrary occupation and a specific environmental policy shock (i.e. a specific EPS-change), we can derive an employment response with corresponding standard error by using the green potential measure $\hat{\eta}_{i}$, the estimated regression coefficients $\hat{\beta}_{1}$ and $\hat{\beta}_{2}$, as well as the estimator covariancematrix from the baseline model specification in column (3) of Table 4 . As before, we choose an average EPS-change equal to $\Delta_{., .}^{E P S} * E P S_{., .}=0.069 * 1.9=0.131$ to illustrate the environmental policy shock. Formally, we calculate occupational employment responses as:

\footnotetext{
${ }^{27}$ The mean of country-level averages of the implicit pollution tax is $28.2 \$$ per ton of $\mathrm{CO}_{2}$ equivalents. That is, a change of the implicit pollution tax by $1 \$$ is a rather small increase.
} 


$$
\hat{\Delta}_{i}=\hat{\beta}_{1} 0.131+\hat{\beta}_{2} \hat{\eta}_{i} 0.131
$$

Figure 4 presents the predicted employment changes $\hat{\Delta}_{i}$ for all occupations. More specifically, it plots the predicted change of occupational employment $\hat{\Delta}_{i}$ following an average EPS-increase by 0.131 conditional on an occupation's green potential $\hat{\eta}_{i}$. The black dotted lines in Figure 4 state if predicted employment changes are significantly different from zero on the $90 \%$ significance level. ${ }^{28}$ Further, the size of the bubbles indicates the average of occupational employment levels across countries and over time, formally $\mathrm{emp}_{i, .}$.

Figure 4: Predicted Employment Changes Following an Environmental Policy Shock

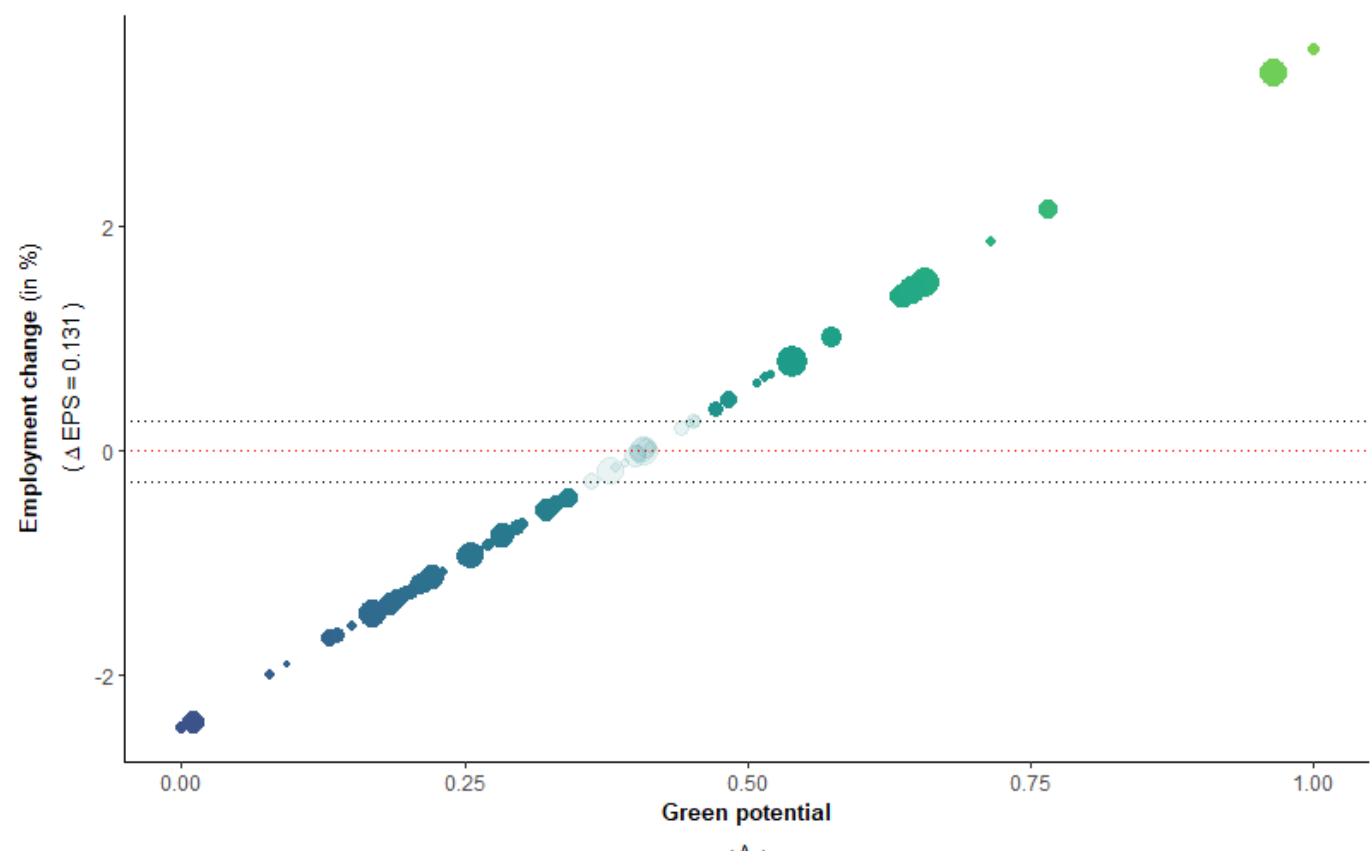

$\left(\hat{\eta}_{\mathrm{i}}\right)$

Note: The graph plots the predicted employment response resulting from $\triangle E P S=0.131$. The size of the points

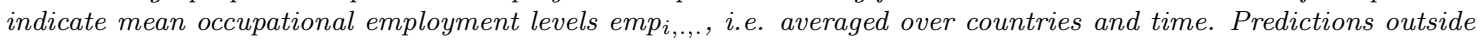
the area between the two black dotted lines are significantly different from zero on the $90 \%$ confidence level.

As previously discussed, the top- and bottom-ranked occupations are expected to experience employment changes by $3.6 \%$ and $-2.5 \%$, respectively. These two occupations define the range of the occupational employment response and are thus located in the upper right and lower left of Figure 4 . For the remaining occupations, predicted employment changes are mostly concentrated between $-2 \%$ and $+2 \%$ and are distributed relatively uniformly over this spectrum. The two highest ranked occupational groups are "211 Physicists, chemists and related professionals" and "214 Architects, engineers and related professionals". Both groups are expected to experience by far the largest employment changes when environmental policy stringency increases. After these two, there is a group of occupations with green potential values $\hat{\eta}_{i}$ between 0.5 and 0.75 , which

\footnotetext{
${ }^{28}$ Significance levels can be obtained through calculating the variance of the predicted employment responses as $\operatorname{Var}\left(\hat{\Delta}_{i}\right)=(0.131)^{2} \operatorname{Var}\left(\hat{\beta}_{1}\right)+(0.131)^{2} \hat{\eta}_{i}^{2} \operatorname{Var}\left(\hat{\beta}_{2}\right)+2(0.131)^{2} \hat{\eta}_{i} \operatorname{Cov}\left(\hat{\beta}_{1}, \hat{\beta}_{2}\right)$
} 
are expected to witness smaller but still positive employment changes, ranging from around $0.5 \%$ to $2 \%$.

This is somewhat different for occupations with negative predicted employment changes. In terms of their green potential, they are located more closely to each other: The spectrum of green potential ranges from 0 to 0.3 only for these occupations ( 0.5 to 1 for occupations with positive effects). Significant negative employment changes range from $-2.5 \%$ to around $-0.7 \%$. In this regard, it is worth mentioning that most of the occupations in this part of the green potential distribution are from the ISCO major groups "8 Plant and machine operators and assemblers", "9 Elementary occupations" and "4 Clerical support workers". This indicates that greening the economy could harm occupations primarily performing support and elementary tasks, while, at the same time, more technically-oriented occupations in manufacturing will likely benefit.

From Figure 4, one can immediately see that employment levels (i.e. the size of the bubbles) are far from uniform across occupations. Therefore, absolute occupational employment changes will vary between occupations. To get a sense of absolute occupational employment changes, we turn to the absolute magnitude of the predicted employment response presented in Figure 4. We use occupational employment levels from 2010 and plot predicted absolute employment changes in Figure 5. For relatively many occupations the projected absolute employment changes tend to be rather small and, accordingly, this is also the case for the aggregated net employment change. This is consistent with previous findings in the literature, indicating that employment changes are small or negligible on aggregate (e.g. Marin and Vona, 2019; Vona et al., 2018). Among the occupations with positive employment changes, it is striking that the occupation "214 Architects, engineers and related professionals" account for $30 \%$ of the total employment increase. In contrast, occupational employment losses are distributed much more evenly. Here, the occupation with the largest absolute employment decrease ("932 Manufacturing labourers") contributes only $14 \%$ to the total employment decrease.

This implies that, on aggregate, the occupational structure primarily determines whether aggregate employment changes are positive or negative. Clearly, the occupational structure in the manufacturing sector differs between countries. Therefore, aggregate employment changes will also be heterogeneous between European countries and there will be winners and losers. In order to analyze this further, we also calculate the country-level employment response resulting from an EPS-change of 0.131. To derive these figures, we use Equation (9): For country $j$, the net employment response from increased environmental policy stringency is defined as the sum of all absolute occupation-level employment changes in that country:

$$
\hat{\Delta}_{j}=\sum_{i=1}^{N} \hat{\Delta}_{i} L_{i j}
$$

In Figure 6 we use occupational employment levels $L_{i j}$ from 2010 and state relative country-level 
Figure 5: Predicted Absolute Employment Changes Following an Environmental Policy Shock

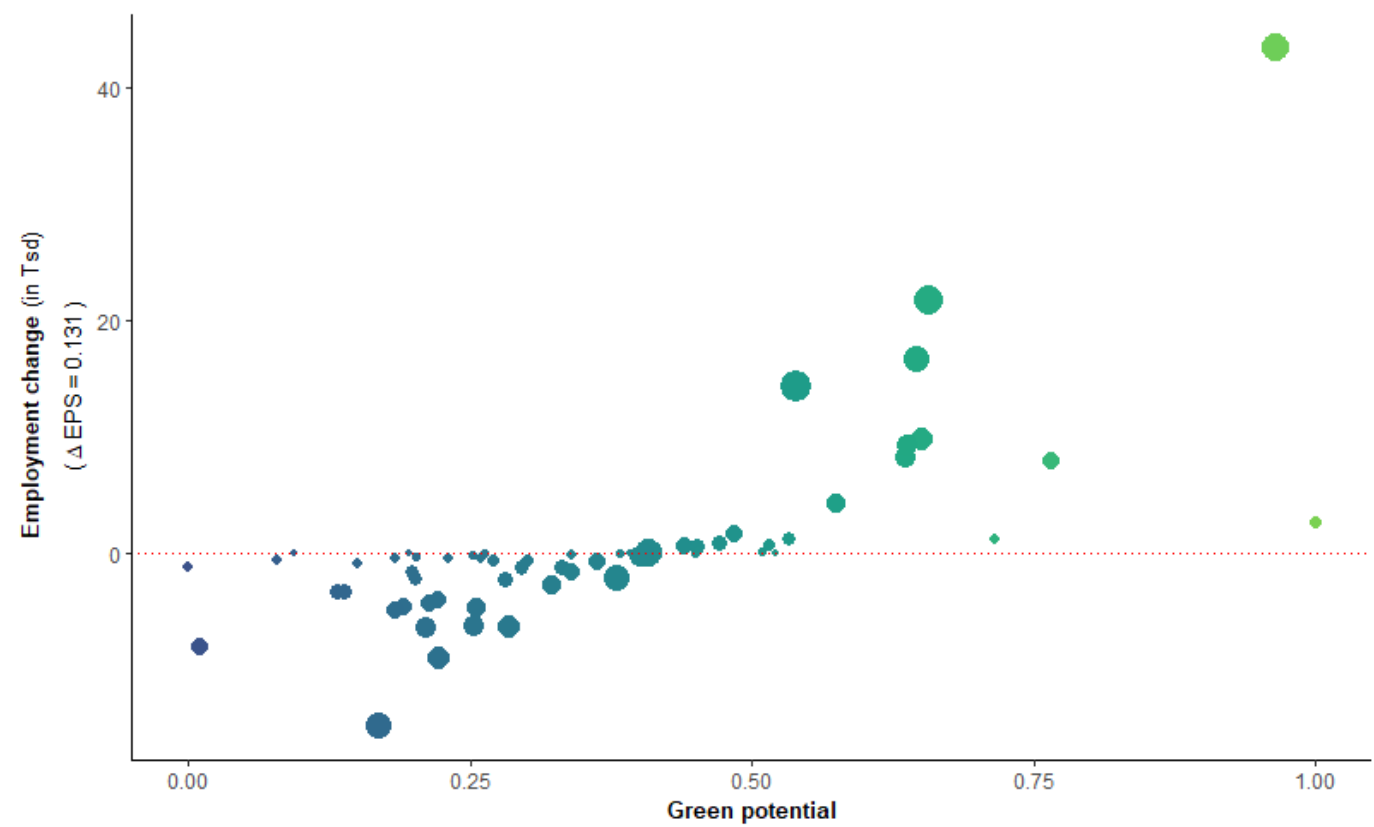

$\left(\hat{\eta}_{\mathrm{i}}\right)$

Note: The graph plots the predicted absolute employment change (in thousand workers) resulting from

$\triangle E P S=0.131$. Predictions are based on 2010 employment figures. The size of the bubbles indicate employment levels in 2010.

employment changes associated with an average environmental policy shock. ${ }^{29}$

This clearly shows varying employment changes across countries. The reason for this is that occupational patterns of national manufacturing sectors are important. In other words, countries whose manufacturing sector employed a relatively large number of occupations with high green potential in 2010, were much more likely to experience net employment gains if environmental policy stringency has increased. According to our illustrative example, this would be the case for primarily the Scandinavian countries, Belgium, Germany, France and Switzerland, as well as the UK and Ireland. Our illustrative example suggests that a shock to the EPS by 0.131 fosters net manufacturing employment in these countries in the range of $0.2 \%-0.55 \%$. A second group of countries could be more or less unaffected by more stringent regulations. This group is composed of the Eastern European countries of Hungary, Slovakia and the Czech Republic, together with Austria and the Netherlands. For these countries, the aggregate net employment responses range from slightly negative but close to $0 \%$ to a maximum of $+0.2 \%$. Lastly, there is a group consisting of Spain, Italy, Greece and Portugal. These four Southern European countries would most likely be negatively affected by increased environmental policies. Their aggregate net employment response ranges from $0 \%$ to around $0.45 \%$ and is most clearly negative for Greece and Portugal.

\footnotetext{
${ }^{29}$ Figure 6 also states confidence intervals for the predicted employment responses. In order to construct these, we have to assume independence across occupational employment responses. In other words, in country $j$, the predicted change of occupation $I S C O_{1 j}$ is unrelated to the predicted change of occupation $I S C O_{2 j}$. With this, significance levels and confidence intervals can again be obtained through calculating the variance of the predicted aggregate employment responses as $\operatorname{Var}\left(\hat{\Delta}_{j}\right)=\sum_{i=1}^{N}\left(L_{i j}\right)^{2} \operatorname{Var}\left(\hat{\Delta}_{i}\right)$
} 
Figure 6: Predicted Aggregate Employment Changes Following an Environmental Policy Shock

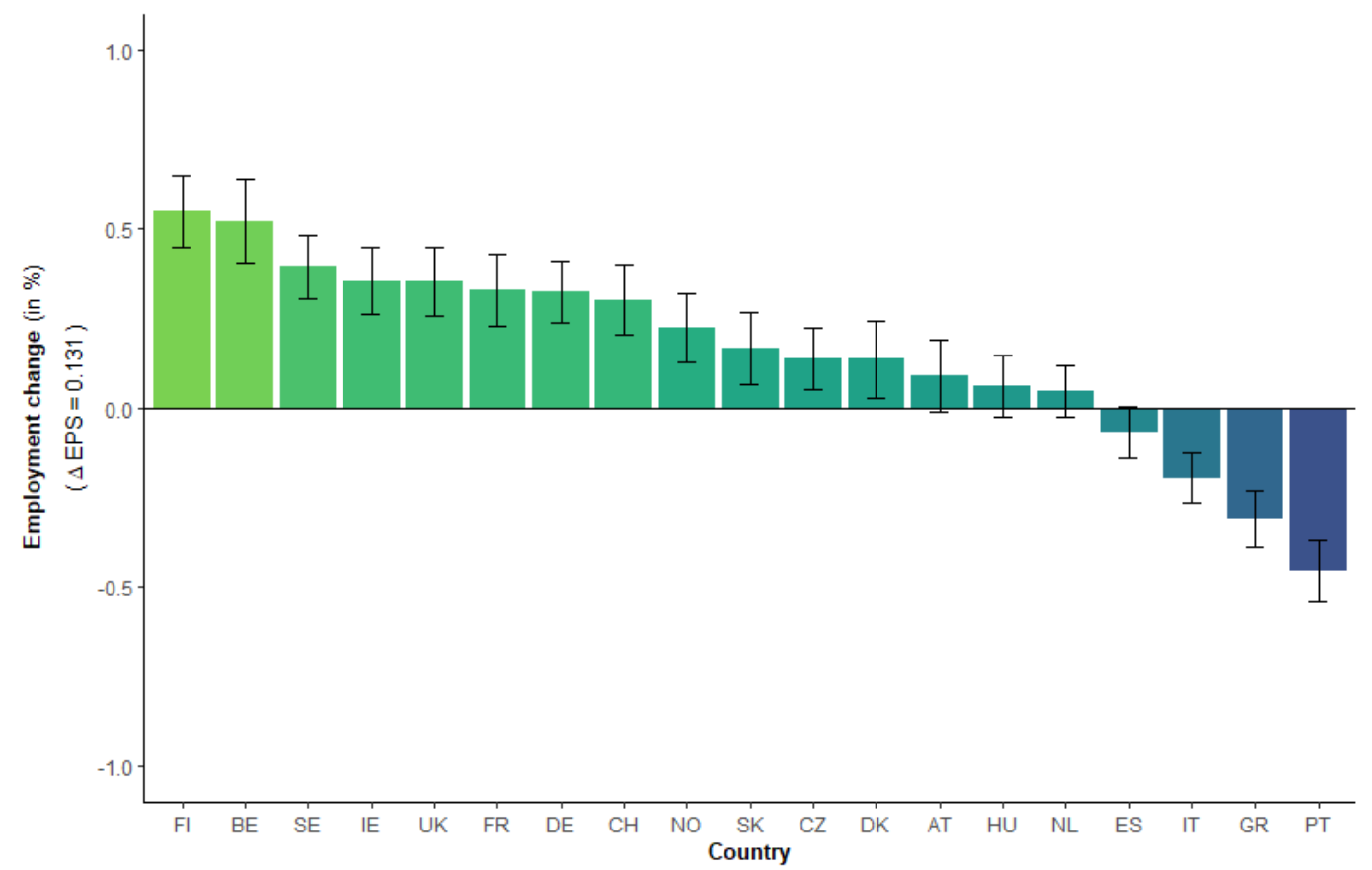

Note: The graph plots the predicted aggregate employment changes from $\triangle E P S=0.131$. The employment changes are based on occupational employment figures from 2010. The vertical error bars show $90 \%$ confidence intervals for the estimated employment changes.

\section{Conclusion}

Since the end of the 1990s, the stringency of environmental policies has steadily increased in many developed countries. For the U.S., there are several studies investigating potential effects on productivity and the labor market from this ongoing regulatory trend. At the same time, empirical evidence for European countries is-with a few exceptions (e.g. Marin and Vona, 2019)rather scarce.

Our paper contributes to this literature in two ways: First, it presents a data-driven approach to predict the green potential of ISCO occupations. Second, it uses this information to investigate the relationship between environmental regulations and occupation-level employment in European manufacturing sectors. In particular, we combine panel data from the OECD and Eurostat for the years 1992-2010 to estimate a fixed effects model using an instrumental variable approach. We capture environmental policy stringency by using the EPS index developed at the OECD (see Botta and Koźluk, 2014). As this measure aggregates a wide range of environmental policies, our regression estimates highlight employment responses of the overall green regulatory stringency. Stated differently, our paper does not analyze the effect of a single and very specific policy intervention.

Our empirical results are robust against several robustness checks and suggest the following: Increased environmental policy stringency negatively affects occupations with low green potential, while it is positively associated with employment in occupations with high green potential. Moreover, we find that average manufacturing employment across occupations remains unaffected 
by environmental policies. All of these results are consistent with Vona et al. (2018), who find the same patterns for the U.S.. Furthermore, our findings are also in line with the results from Marin and Vona (2019) for European labor markets, although we focus on a more granular occupational level and use a different empirical framework. Thus, our analysis complements these papers and adds additional empirical insights on the importance of heterogeneous labor market responses resulting from greening.

We also illustrate the implications of our findings in response to a specific shock to the stringency of green regulations. According to our estimates, an average increase in the OECD's EPS index results in occupational employment responses ranging from $-2.5 \%$ to $+3.6 \%$. That is to say, we find substantial heterogeneity between occupations. Accordingly, there are winners and losers among manufacturing workers. To be more specific, our estimates suggest that science, engineering and technical occupations are expected to benefit from greening, while elementary occupations and clerical support workers could lose. Furthermore, since occupational patterns differ between countries, heterogeneous net employment responses also translate to the country-level. In other words, whether a country benefits or loses from a green transition and its inherent policy changes depends largely on the occupational structure of the country. At least in the short term, a green transition could thus also create winners and losers across countries. Taken together, our analysis provides insight into the distributional consequences of greening the economy. Such distributional effects are especially relevant from a political economy perspective, as they could provide a starting point to explain public opposition against more stringent environmental regulations from unions, industries, regions and even countries. In fact, some studies focusing on greening at the more regional level have recently emerged (e.g. Santoalha and Boschma, 2020; Barbieri and Consoli, 2019; Bohlmann et al., 2019) and we consider this an interesting direction for future research. 


\section{Acknowledgments}

We are grateful for comments and suggestions by Dragan Filimonovic, Michael Lobsiger, Rolf Weder, Beat Hintermann, Aya Kachi and participants of the University of Basel SCCER lunch. Furthermore, we benefited from valuable input of participants of the 2020 Swiss National Science Foundation's NRP-73 conference and we are thankful for the input of two anonymous reviewers for the Young Economists Spring Meeting 2020 conference.

\section{Computational Details}

Our empirical results were obtained using R (version 3.6.1) (see R Core Team, 2019). We have trained the Ridge regression algorithm using the package glmnet (Simon et al., 2011). All subsequent fixed effects regressions were estimated with the package plm (Millo, 2017; Croissant et al., 2008). Moreover, for data processing and data visualization we have relied mainly on the packages dplyr (Wickham et al., 2018) and ggplot2 (Wickham, 2016).

\section{References}

Albrizio, S., Kozluk, T., Zipperer, V., 2017. Environmental policies and productivity growth: Evidence across industries and firms. Journal of Environmental Economics and Management 81, 209-226.

Autor, D. H., Dorn, D., 2013. The growth of low-skill service jobs and the polarization of the US labor market. The American Economic Review, 1553-1597.

Autor, D. H., Dorn, D., Hanson, G. H., 2013. The china syndrome: Local labor market effects of import competition in the United States. The American Economic Review, 2121-2168.

Barbieri, N., Consoli, D., 2019. Regional diversification and green employment in us metropolitan areas. Research Policy 48 (3), 693-705.

Berman, E., Bui, L. T., 2001a. Environmental regulation and labor demand: Evidence from the south coast air basin. Journal of Public Economics 79 (2), 265-295.

Berman, E., Bui, L. T., 2001b. Environmental regulation and productivity: evidence from oil refineries. Review of Economics and Statistics 83 (3), 498-510.

Blinder, A. S., Krueger, A. B., 2013. Alternative measures of offshorability: A survey approach. Journal of Labor Economics 31 (S1), S97-S128.

Bohlmann, H. R., Horridge, J. M., Inglesi-Lotz, R., Roos, E. L., Stander, L., 2019. Regional employment and economic growth effects of south africas transition to low-carbon energy supply mix. Energy Policy 128, 830-837.

Botta, E., Koźluk, T., 2014. Measuring environmental policy stringency in OECD countries: A composite index approach. OECD Economics Department Working Papers (1177). 
Bound, J., Jaeger, D. A., Baker, R. M., 1995. Problems with instrumental variables estimation when the correlation between the instruments and the endogenous explanatory variable is weak. Journal of the American Statistical Association 90 (430), 443-450.

Bowen, A., Kuralbayeva, K., 2015. Looking for green jobs: the impact of green growth on employment. Policy Brief. Grantham Research Institute on Climate Change. London School of Economics.

Bowen, A., Kuralbayeva, K., Tipoe, E. L., 2018. Characterising green employment: The impacts of 'greening' on workforce composition. Energy Economics 72, 263-275.

Cai, W., Wang, C., Chen, J., Wang, S., 2011. Green economy and green jobs: Myth or reality? the case of Chinas power generation sector. Energy 36 (10), 5994-6003.

Cainelli, G., Mazzanti, M., 2013. Environmental innovations in services: Manufacturing-services integration and policy transmissions. Research Policy 42 (9), 1595-1604.

CEDEFOP, 2013. Quantifying skill needs in Europe. CEDEFOP Research Paper (30), 1-144.

Chay, K. Y., Greenstone, M., 2003. The impact of air pollution on infant mortality: evidence from geographic variation in pollution shocks induced by a recession. The Quarterly Journal of Economics 118 (3), 1121-1167.

Cole, M. A., Elliott, R. J., 2007. Do environmental regulations cost jobs? An industry-level analysis of the UK. The BE Journal of Economic Analysis \& Policy 7 (1).

Consoli, D., Marin, G., Marzucchi, A., Vona, F., 2016. Do green jobs differ from non-green jobs in terms of skills and human capital? Research Policy 45 (5), 1046-1060.

Croissant, Y., Millo, G., et al., 2008. Panel data econometrics in R: The plm package. Journal of Statistical Software 27 (2), 1-43.

Dierdorff, E. C., Norton, J. J., Drewes, D. W., Kroustalis, C. M., Rivkin, D., Lewis, P., 2009. Greening of the world of work: Implications for O*NET-SOC and new and emerging occupations. O* NET, February.

Eichengreen, B., 2010. The breakup of the euro area. In: Europe and the Euro. University of Chicago Press, pp. 11-51.

Franco, C., Marin, G., 2017. The effect of within-sector, upstream and downstream environmental taxes on innovation and productivity. Environmental and Resource Economics 66 (2), 261-291.

Goos, M., Manning, A., Salomons, A., 2009. Job polarization in Europe. American Economic Review 99 (2), 58-63.

Goos, M., Manning, A., Salomons, A., 2014. Explaining job polarization: Routine-biased technological change and offshoring. American Economic Review 104 (8), 2509-26. 
Greaker, M., 2006. Spillovers in the development of new pollution abatement technology: a new look at the porter-hypothesis. Journal of Environmental Economics and Management 52 (1), 411-420.

Greenstone, M., 2002. The impacts of environmental regulations on industrial activity: Evidence from the 1970 and 1977 clean air act amendments and the census of manufactures. Journal of Political Economy 110 (6), 1175-1219.

Gregory, T., Salomons, A., Zierahn, U., 2018. Racing with or against the machine? Evidence from Europe. CESifo Working Paper (7247).

Hastie, T., Friedman, J., Tibshirani, R., 2009. The Elements of Statistical Learning: Data Mining, Inference, and Prediction. Springer.

Isen, A., Rossin-Slater, M., Walker, W. R., 2017. Every breath you take - every dollar you'll make: The long-term consequences of the clean air act of 1970. Journal of Political Economy 125 (3), 848-902.

Jaffe, A. B., Palmer, K., 1997. Environmental regulation and innovation: A panel data study. Review of Economics and Statistics 79 (4), 610-619.

Lane, P. R., 2012. The European sovereign debt crisis. Journal of Economic Perspectives 26 (3), $49-68$.

Leiter, A. M., Parolini, A., Winner, H., 2011. Environmental regulation and investment: Evidence from european industry data. Ecological Economics 70 (4), 759-770.

Marin, G., Vona, F., 2019. Climate policies and skill-biased employment dynamics: Evidence from eu countries. Journal of Environmental Economics and Management 98, 102253.

Martinez-Fernandez, C., Hinojosa, C., Miranda, G., 2010. Green jobs and skills: The local labour market implications of addressing climate change. Working Document, CFE/LEED OECD.

Millo, G., 2017. Robust standard error estimators for panel models: A unifying approach. Journal of Statistical Software 82 (3), 1-27.

OECD, 2017. Getting Skills Right: Skills for Jobs Indicators. OECD Publishing.

Porter, M. E., van der Linde, C., 1995. Toward a new conception of the environmentcompetitiveness relationship. Journal of Economic Perspectives 9 (4), 97-118.

R Core Team, 2019. R: A Language and Environment for Statistical Computing. R Foundation for Statistical Computing, Vienna, Austria.

Rutzer, C., Niggli, M., Weder, R., 2020. Estimating the green potential of occupations: A new approach applied to the us labor market. WWZ Working Paper 2020 (03).

Santoalha, A., Boschma, R., 2020. Diversifying in green technologies in european regions: does political support matter? Regional Studies, 1-14. 
Simon, N., Friedman, J., Hastie, T., Tibshirani, R., 2011. Regularization paths for cox's proportional hazards model via coordinate descent. Journal of Statistical Software 39 (5), 1-13.

Verdolini, E., Vona, F., Popp, D., 2018. Bridging the gap: Do fast-reacting fossil technologies facilitate renewable energy diffusion? Energy Policy 116, 242-256.

Vona, F., Marin, G., Consoli, D., Popp, D., 2018. Environmental regulation and green skills: An empirical exploration. Journal of the Association of Environmental and Resource Economists.

Walker, W. R., 2013. The transitional costs of sectoral reallocation: Evidence from the clean air act and the workforce. The Quarterly Journal of Economics 128 (4), 1787-1835.

Wickham, H., 2016. ggplot2: Elegant graphics for data analysis. Springer.

Wickham, H., Franois, R., Henry, L., Mller, K., 2018. dplyr: A Grammar of Data Manipulation. $\mathrm{R}$ package version 0.7 .8 .

Yamazaki, A., 2017. Jobs and climate policy: Evidence from british columbia's revenue-neutral carbon tax. Journal of Environmental Economics and Management 83, 197 - 216. 


\section{A Appendix}

\section{A.1 Transferring Skills from O*NET to ISCO}

In the following, we explain in detail the transfer of skills from 8-digit O*NET to ISCO-88. There exist official crosswalks between the 6 -digit SOC and 4-digit ISCO-08 classification system provided, for example, by the US Bureau of Labor Statistics (BLS). However, O*NET occupations are classified according to the US 8-digit SOC code. So the first thing we have to do is to transfer the skills from 8-digit to 6-digit SOC. In order to achieve this, we follow the literature (Bowen et al., 2018; Vona et al., 2018; Consoli et al., 2016) and take simple (unweighted) averages of each skill value $s$ of all 8-digit $\mathrm{O}^{*} \mathrm{NET}$ occupations belonging to a 6 -digit $\mathrm{SOC}$ occupation. In the next step, we use the existing crosswalk between the 6-digit US SOC and the 4-digit ISCO-08 to transfer each skill value $s$ from SOC to ISCO-08. There are multiple matches on both sides, i.e., several SOC occupations are matched to an ISCO-08 occupation and vice versa. To deal with this, we follow again the literature (OECD, 2017; Goos et al., 2014) and transfer the value of a skill $s$ from 6-digit SOC to 4-digit ISCO-08 by using a simple (unweighted) average among multiple matches. Applying this transformation, we end up with a value for each skill $s$ for all occupations for which a cross-walk between 6-digit SOC and 4-digit ISCO-08 exists. The correlation of skill values of 6-digit SOC occupations that match with the same 4-digit ISCO-08 occupation is on average 0.958 and the standard deviation, 0.052 . The high correlation indicates very similar skill values between multiple matches. Thus, using simple averages to transfer skills from 6-digit SOC to 4-digit ISCO-08 seems a valid approach to deal with multiple matches.

From this point on, there are a few more steps to go. Since our employment data from the European Union Labour Force Survey (ELFS) is only available at a 3-digit level, we have to aggregate the skill values from 4-digit to the 3-digit ISCO-08 level. To achieve this, we again take simple (unweighted) averages of each skill value $s$ of all 4-digit ISCO-08 occupations belonging to a 3-digit ISCO-08 occupation. As in the case of SOC-occupations, each 4-digit occupation belongs

to exactly one 3-digit ISCO-08 occupation. Finally, we have to transfer the skills from 3-digit ISCO-08 to 3-digit ISCO-88. Again, there are multiple matches in both directions. Thus, as in the previous steps, we take simple (unweighted) averages. Finally, we end up with having a value for all 114 O*NET skills for each of the 3-digit ISCO-88 occupations. 


\section{A.2 Tables}

Table 9: Coefficients of the Ridge regression

\begin{tabular}{|c|c|}
\hline General Skills from $\mathrm{O}^{*} \mathrm{NET}$ & Ridge coefficients \\
\hline Achievement & 0.07 \\
\hline Active Learning & -0.01 \\
\hline Active Listening & -0.03 \\
\hline Administration and Management & 0.01 \\
\hline Analyzing Data or Information & 0.04 \\
\hline Assisting and Caring for Others & -0.05 \\
\hline Biology & 0.05 \\
\hline Building and Construction & 0.16 \\
\hline Chemistry & 0.06 \\
\hline Clerical & 0.02 \\
\hline Coaching and Developing Others & -0.01 \\
\hline Communicating with Persons Outside Organization & 0.04 \\
\hline Communicating with Supervisors Peers or Subordinates & 0.03 \\
\hline Communications and Media & 0.02 \\
\hline Complex Problem Solving & -0.04 \\
\hline Computers and Electronics & -0.02 \\
\hline Controlling Machines and Processes & -0.08 \\
\hline Coordinating the Work and Activities of Others & 0.06 \\
\hline Coordination & -0.03 \\
\hline Critical Thinking & -0.01 \\
\hline Customer and Personal Service & -0.04 \\
\hline Design & 0.02 \\
\hline Developing and Building Teams & 0.06 \\
\hline Developing Objectives and Strategies & 0.01 \\
\hline Documenting Recording Information & 0.03 \\
\hline Economics and Accounting & 0.07 \\
\hline Education and Training & -0.01 \\
\hline Engineering and Technology & 0.07 \\
\hline English Language & -0.02 \\
\hline Equipment Maintenance & 0.02 \\
\hline Equipment Selection & -0.03 \\
\hline Establishing and Maintaining Interpersonal Relationships & -0.02 \\
\hline Estimating the Quantifiable Characteristics of Products Events or Information & 0.02 \\
\hline Evaluating Information to Determine Compliance with Standards & 0.05 \\
\hline Fine Arts & -0.10 \\
\hline Food Production & -0.03 \\
\hline Foreign Language & -0.08 \\
\hline
\end{tabular}


$\begin{array}{ll}\text { Geography } & 0.08\end{array}$

Handling and Moving Objects $\quad-0.04$

History and Archeology $\quad-0.03$

Identifying Objects Actions and Events $\quad-0.05$

Independence $\quad-0.03$

Inspecting Equipment Structures or Material $\quad 0.01$

$\begin{array}{ll}\text { Installation } & 0.05\end{array}$

Instructing $\quad-0.01$

$\begin{array}{ll}\text { Interacting With Computers } & 0.01\end{array}$

Interpreting the Meaning of Information for Others $\quad 0.03$

Judging the Qualities of Things Services or People $\quad-0.03$

Judgment and Decision Making $\quad-0.01$

Law and Government $\quad 0.06$

Learning Strategies $\quad-0.03$

Making Decisions and Solving Problems $\quad-0.04$

Management of Financial Resources $\quad 0.05$

$\begin{array}{ll}\text { Management of Material Resources } & 0.03\end{array}$

Management of Personnel Resources $\quad 0.01$

$\begin{array}{ll}\text { Mathematics } & 0.01\end{array}$

$\begin{array}{lr}\text { Mechanical } & 0.06\end{array}$

$\begin{array}{ll}\text { Medicine and Dentistry } & -0.07\end{array}$

Monitor Processes Materials or Surroundings $\quad 0.03$

$\begin{array}{ll}\text { Monitoring } & 0.02\end{array}$

Monitoring and Controlling Resources 0.03

$\begin{array}{ll}\text { Negotiation } & 0.05\end{array}$

Operating Vehicles Mechanized Devices or Equipment 0.04

$\begin{array}{ll}\text { Operation and Control } & 0.02\end{array}$

$\begin{array}{ll}\text { Operation Monitoring } & 0.01\end{array}$

Operations Analysis $\quad-0.08$

Organizing Planning and Prioritizing Work $\quad-0.02$

Performing Administrative Activities $\quad-0.04$

$\begin{array}{lr}\text { Performing General Physical Activities } & 0.02\end{array}$

Personnel and Human Resources $\quad-0.03$

$\begin{array}{lr}\text { Persuasion } & 0.06\end{array}$

$\begin{array}{ll}\text { Philosophy and Theology } & -0.04\end{array}$

$\begin{array}{ll}\text { Physics } & 0.08\end{array}$

$\begin{array}{ll}\text { Production and Processing } & -0.02\end{array}$

$\begin{array}{lr}\text { Programming } & 0.06\end{array}$

$\begin{array}{ll}\text { Provide Consultation and Advice to Others } & 0.06\end{array}$

$\begin{array}{ll}\text { Psychology } & -0.03\end{array}$

$\begin{array}{ll}\text { Public Safety and Security } & 0.07\end{array}$ 
$\begin{array}{ll}\text { Quality Control Analysis } & 0.01\end{array}$

Reading Comprehension $\quad 0.02$

$\begin{array}{lr}\text { Recognition } & 0.01\end{array}$

$\begin{array}{ll}\text { Relationships } & -0.03\end{array}$

$\begin{array}{lr}\text { Repairing } & 0.01\end{array}$

Repairing and Maintaining Electronic Equipment $\quad-0.02$

Repairing and Maintaining Mechanical Equipment $\quad-0.01$

$\begin{array}{lr}\text { Sales and Marketing } & 0.01\end{array}$

Scheduling Work and Activities $\quad 0.01$

$\begin{array}{lr}\text { Science } & 0.03\end{array}$

Selling or Influencing Others $\quad 0.05$

Social Perceptiveness $\quad-0.05$

Sociology and Anthropology $\quad-0.02$

Speaking $\quad-0.02$

Staffing Organizational Units $\quad-0.03$

Support $\quad-0.14$

$\begin{array}{ll}\text { Systems Analysis } & 0.06\end{array}$

$\begin{array}{ll}\text { Systems Evaluation } & 0.05\end{array}$

Technology Design $\quad-0.01$

$\begin{array}{ll}\text { Telecommunications } & -0.07\end{array}$

Therapy and Counseling $\quad-0.05$

Thinking Creatively $\quad-0.02$

Time Management $\quad-0.03$

$\begin{array}{ll}\text { Training and Teaching Others } & -0.03\end{array}$

$\begin{array}{ll}\text { Transportation } & 0.01\end{array}$

$\begin{array}{ll}\text { Troubleshooting } & 0.02\end{array}$

Updating and Using Relevant Knowledge $\quad-0.01$

$\begin{array}{ll}\text { Working Conditions } & 0.05\end{array}$

$\begin{array}{ll}\text { Writing } & 0.05\end{array}$ 
Table 10: Estimated Green Potential of all 3-digit ISCO-88 Occupations

\begin{tabular}{|c|c|c|}
\hline ISCO-88 & Occupation & Estimated green potential \\
\hline 211 & Physicists, chemists and related professionals & 1.00 \\
\hline 214 & Architects, engineers and related professionals & 0.96 \\
\hline 111 & Legislators and senior government officials & 0.85 \\
\hline 114 & Senior officials of special-interest organisations & 0.85 \\
\hline 712 & Building frame and related trades workers & 0.77 \\
\hline 711 & Miners, shotfirers, stone cutters and carvers & 0.71 \\
\hline 723 & Machinery mechanics and fitters & 0.66 \\
\hline 123 & Other specialist managers & 0.65 \\
\hline 828 & Assemblers & 0.64 \\
\hline 724 & Electrical and electronic equipment mechanics and fitters & 0.64 \\
\hline 122 & Production and operations managers & 0.63 \\
\hline 212 & Mathematicians, statisticians and related professionals & 0.63 \\
\hline 615 & Fishery workers, hunters and trappers & 0.58 \\
\hline 713 & Building finishers and related trades workers & 0.57 \\
\hline 311 & Physical and engineering science technicians & 0.54 \\
\hline 312 & Computer associate professionals & 0.53 \\
\hline 221 & Life science professionals & 0.52 \\
\hline 342 & Business services agents and trade brokers & 0.51 \\
\hline 321 & Life science technicians and related associate professional & 0.51 \\
\hline 931 & Mining and construction labourers & 0.49 \\
\hline 829 & Other machine operators not elsewhere classified & 0.48 \\
\hline 314 & Ship and aircraft controllers and technicians & 0.47 \\
\hline 213 & Computing professionals & 0.46 \\
\hline 811 & Mining and mineral-processing-plant operators & 0.46 \\
\hline 344 & Customs, tax and related government associate professionals & 0.46 \\
\hline 714 & Painters, building structure cleaners and related trades workers & 0.45 \\
\hline 315 & Safety and quality inspectors & 0.45 \\
\hline 611 & Market gardeners and crop growers & 0.44 \\
\hline 241 & Business professionals & 0.44 \\
\hline 613 & Crop and animal producers & 0.44 \\
\hline 614 & Forestry and related workers & 0.43 \\
\hline 732 & Potters, glass-makers and related trades workers & 0.41 \\
\hline 522 & Shop, stall and market salespersons and demonstrators & 0.41 \\
\hline 341 & Finance and sales associate professionals & 0.41 \\
\hline 721 & Metal moulders, welders, sheet-metal workers & 0.41 \\
\hline 833 & Agricultural and other mobile plant operators & 0.40 \\
\hline 821 & Metal- and mineral-products machine operators & 0.40 \\
\hline 921 & Agricultural, fishery and related labourers & 0.40 \\
\hline
\end{tabular}


$816 \quad$ Power-production and related plant operators $\quad 0.39$

834 Ships' deck crews and related workers $\quad 0.39$

$733 \quad$ Handicraft workers in wood, textile, leather and related materials $\quad 0.38$

$722 \quad$ Blacksmiths, tool-makers and related trades workers $\quad 0.38$

$812 \quad$ Metal-processing plant operators 0.36

$612 \quad$ Animal producers and related workers $\quad 0.34$

$347 \quad$ Artistic, entertainment and sports associate professionals 0.34

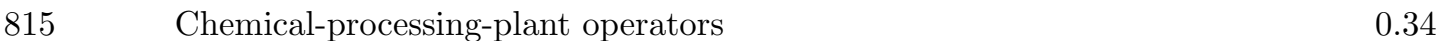

$731 \quad$ Precision workers in metal and related materials $\quad 0.33$

$742 \quad$ Wood treaters, cabinet-makers and related trades workers $\quad 0.32$

$231 \quad$ College, university and higher education teaching professionals $\quad 0.31$

$243 \quad$ Archivists, librarians and related information professionals $\quad 0.31$

$\begin{array}{ll}246 \quad \text { Religious professionals } & 0.30\end{array}$

$813 \quad$ Glass, ceramics and related plant operators $\quad 0.30$

$822 \quad$ Chemical-products machine operators 0.29

814 Wood-processing- and papermaking-plant operators $\quad 0.29$

$313 \quad$ Optical and electronic equipment operators $\quad 0.29$

$413 \quad$ Material-recording and transport clerks $\quad 0.28$

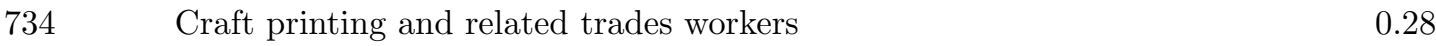

$\begin{array}{llr}516 & \text { Protective services workers } & 0.26\end{array}$

$242 \quad$ Legal professionals $\quad 0.26$

824 Wood-products machine operators $\quad 0.26$

$743 \quad$ Textile, garment and related trades workers $\quad 0.25$

$245 \quad$ Writers and creative or performing artists $\quad 0.25$

$827 \quad$ Food and related products machine operators $\quad 0.25$

$916 \quad$ Garbage collectors and related labourers $\quad 0.24$

$232 \quad$ Secondary education teaching professionals $\quad 0.24$

$\begin{array}{lll}334 & \text { Other teaching associate professionals } & 0.23\end{array}$

$244 \quad$ Social science and related professionals $\quad 0.23$

$222 \quad$ Health professionals (except nursing) 0.22

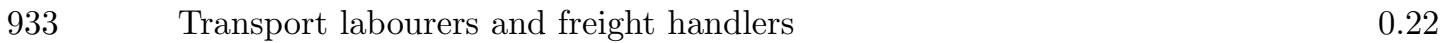

$\begin{array}{lll}741 & \text { Food processing and related trades workers } & 0.22\end{array}$

$\begin{array}{lll}832 & \text { Motor vehicle drivers } & 0.21\end{array}$

$343 \quad$ Administrative associate professionals $\quad 0.21$

$831 \quad$ Locomotive engine drivers and related workers $\quad 0.20$

$512 \quad$ Housekeeping and restaurant services workers $\quad 0.20$

825 Printing-, binding- and paper-products machine operators 0.20

$\begin{array}{llr}911 & \text { Street vendors and related workers } & 0.20\end{array}$

$421 \quad$ Cashiers, tellers and related clerks $\quad 0.20$

$744 \quad$ Pelt, leather and shoemaking trades workers $\quad 0.20$

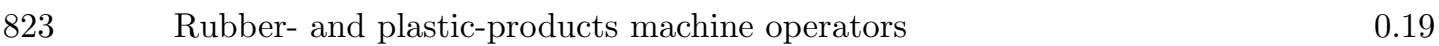


$915 \quad$ Messengers, porters, doorkeepers and related workers 0.18

$826 \quad$ Textile-, fur- and leather-products machine operators 0.18

$\begin{array}{lll}932 & \text { Manufacturing labourers } & 0.17\end{array}$

$\begin{array}{lll}345 & \text { Police inspectors and detectives } & 0.17\end{array}$

$322 \quad$ Health associate professionals (except nursing) 0.15

$\begin{array}{lll}514 & \text { Other personal services workers } & 0.14\end{array}$

$\begin{array}{lll}914 & \text { Building caretakers, window and related cleaners } & 0.14\end{array}$

$913 \quad$ Domestic and related helpers, cleaners and launderers 0.14

$412 \quad$ Numerical clerks 0.13

$511 \quad$ Travel attendants and related workers $\quad 0.10$

$234 \quad$ Special education teaching professionals $\quad 0.09$

$\begin{array}{lll}235 & \text { Other teaching professionals } & 0.09\end{array}$

$414 \quad$ Library, mail and related clerks 0.08

$513 \quad$ Personal care and related workers $\quad 0.07$

233 Primary and pre-primary education teaching professionals 0.05

$332 \quad$ Pre-primary education teaching associate professionals 0.05

$\begin{array}{lll}323 & \text { Nursing and midwifery associate professionals } & 0.04\end{array}$

$\begin{array}{lll}346 & \text { Social work associate professionals } & 0.04\end{array}$

$348 \quad$ Religious associate professionals 0.04

$411 \quad$ Secretaries and keyboard-operating clerks $\quad 0.01$

\begin{tabular}{lr}
422 Client information clerks & 0.00 \\
\hline
\end{tabular} 
Table 11: Summary Statistics of the EPS Index

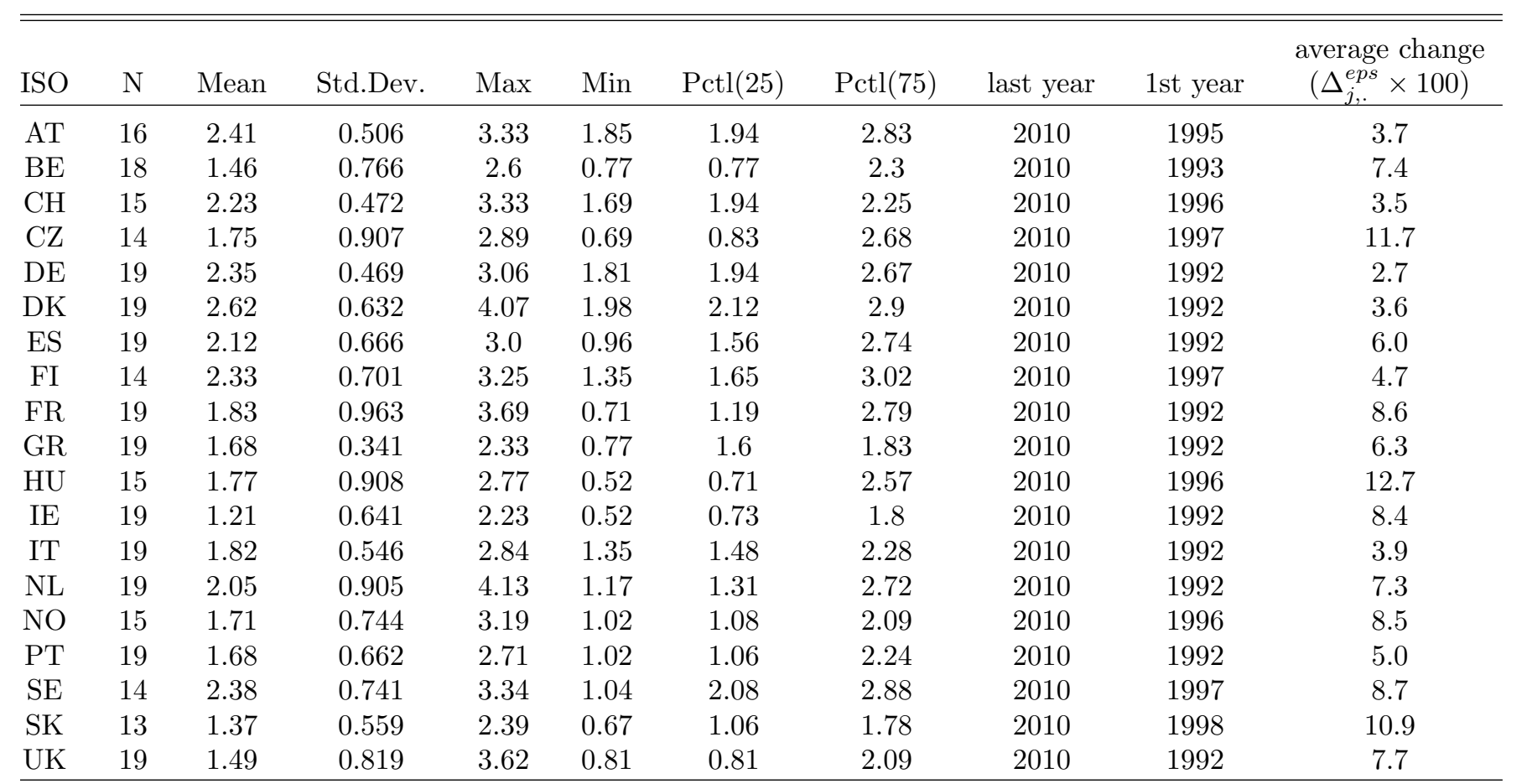

Note: The data is from the OECD. The average growth rate $\Delta_{j, .}^{e p s}$ is calculated as the geometric mean of annual EPS changes. The obtained value is multiplied by 100 to obtain percentage changes. 
Table 12: Number of 3-digit ISCO Occupations per Country

\begin{tabular}{cccc}
\hline \hline ISO & N & last year & 1st year \\
\hline AT & 41 & 2010 & 1995 \\
$\mathrm{BE}$ & 24 & 2010 & 1993 \\
$\mathrm{CH}$ & 26 & 2010 & 1996 \\
$\mathrm{CZ}$ & 54 & 2010 & 1997 \\
$\mathrm{DE}$ & 41 & 2010 & 1992 \\
$\mathrm{DK}$ & 21 & 2010 & 1992 \\
$\mathrm{ES}$ & 48 & 2010 & 1992 \\
$\mathrm{FI}$ & 29 & 2010 & 1997 \\
$\mathrm{FR}$ & 45 & 2010 & 1992 \\
$\mathrm{GR}$ & 40 & 2010 & 1992 \\
$\mathrm{HU}$ & 50 & 2010 & 1996 \\
$\mathrm{IE}$ & 44 & 2010 & 1992 \\
$\mathrm{IT}$ & 50 & 2010 & 1992 \\
$\mathrm{NL}$ & 44 & 2010 & 1992 \\
$\mathrm{NO}$ & 23 & 2010 & 1996 \\
$\mathrm{PT}$ & 36 & 2010 & 1992 \\
$\mathrm{SE}$ & 31 & 2010 & 1997 \\
$\mathrm{SK}$ & 35 & 2010 & 1998 \\
$\mathrm{UK}$ & 39 & 2010 & 1992 \\
\hline
\end{tabular}

Notes: Data is obtained from Eurostat for 19 European countries. N gives the number of occupations per country, which are considered in the regressions. Furthermore, the last two columns state the latest and the first year with employment figures available for occupations from that country.

Table 13: Summary Statistics of Country-Level Control Variables

\begin{tabular}{lccccccc}
\hline \hline Statistic & $\mathrm{N}$ & Mean & St. Dev. & Min & Pctl(25) & Pctl(75) & Max \\
\hline Unemployment rate & 324 & 7.99 & 3.87 & 2.26 & 5.01 & 9.66 & 24.17 \\
$\log$ (patent stock) & 324 & 7.65 & 1.55 & 3.38 & 6.63 & 8.68 & 10.95 \\
$\log$ (trade openness) & 324 & 4.35 & 0.41 & 3.56 & 3.99 & 4.71 & 5.24 \\
Working age to pension age ratio & 311 & 4.31 & 0.59 & 3.14 & 3.94 & 4.49 & 6.41 \\
Female labor force participation rate & 324 & 63.05 & 9.42 & 41.71 & 56.46 & 70.24 & 78.17 \\
$\log$ (manufacturing employment) & 324 & 13.71 & 1.07 & 11.86 & 12.98 & 14.76 & 15.97 \\
$\log$ (total population) & 324 & 16.47 & 0.99 & 15.08 & 15.77 & 17.59 & 18.23 \\
\hline
\end{tabular}

Notes: The data on the unemployment rate, patent stocks, trade openness, working age to pension age ratio and the female labor force participation rate are all obtained from the OECD. Data on manufacturing employment and total population is from Eurostat. 
Table 14: The Impact of Environmental Policy Stringency on Employment (Fixed Effects)

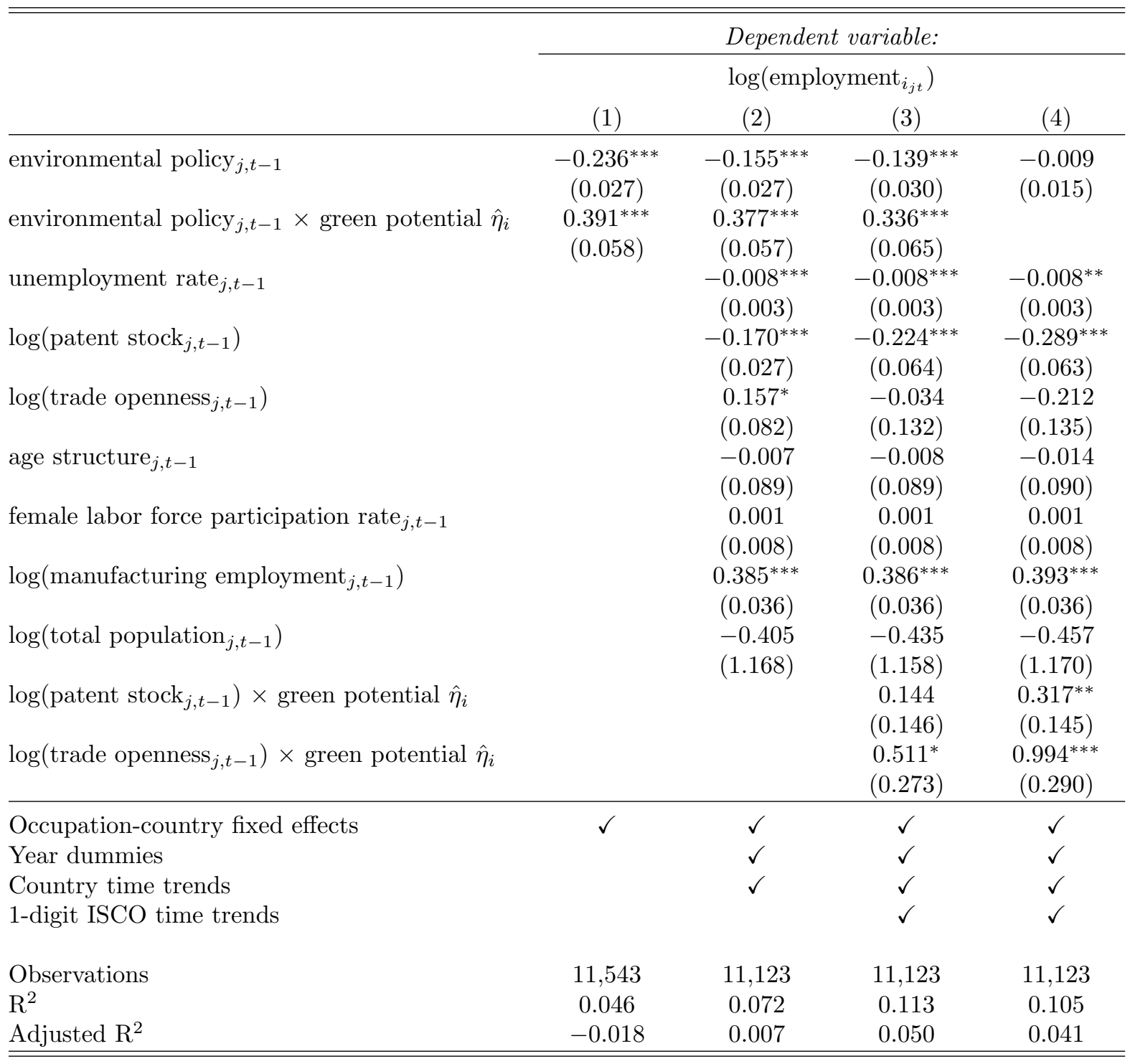

Notes: The sample is an unbalanced panel that covers 19 European countries between 1992 and 2010. The dependent variable in all columns is the log of occupational employment. All model specifications include fixed effects for country-specific occupations. Columns (2) to (4) also include year dummies, country-specific linear time trends and a set of control variables. The controls consist of the national unemployment rate, the logged share of exports plus imports over GDP, the logged patent stock invented by domestic residents, the ratio between the population share of the working age population (16-65 years old) to pensioners $(65+$ years old), the female labor force participation rate as well as the log of total population and the log of total manufacturing employment. In columns (3) and (4) we additionally interact the trade and technology control variables with the green potential measure $\hat{\eta}_{i}$, thereby constructing two new controls on the occupation level. Moreover, columns (3) and (4) also include a linear time trend on the 1-digit ISCO level. Data is from the OECD and Eurostat. Standard errors are clustered at country-specific occupations (721 country-specific ISCO 3-digit occupations) and are robust against heteroskedasticity. Significance levels for the coefficients are indicated as: ${ }^{*} \mathrm{p}<0.1$; ${ }^{* *} \mathrm{p}<0.05 ;{ }^{* * *} \mathrm{p}<0.01$ 
Table 15: Instrument Relevance: G7 Member Countries Excluded (Fixed Effects)

\begin{tabular}{lccc}
\hline \hline & \multicolumn{3}{c}{ Dependent variable: } \\
\cline { 2 - 4 } & \multicolumn{2}{c}{ Domestic environmental policy } \\
& $(1)$ & $(2)$ & $(3)$ \\
\hline Foreign environmental policy & $0.831^{* * *}$ & $0.711^{* * *}$ & $0.768^{* * *}$ \\
& $(0.145)$ & $(0.141)$ & $(0.144)$ \\
\hline Country fixed effects & $\checkmark$ & $\checkmark$ & $\checkmark$ \\
Time trend & $\checkmark$ & $\checkmark$ & $\checkmark$ \\
Business cycle, trade \& technology & & $\checkmark$ & $\checkmark$ \\
Demographic \& sector controls & & & $\checkmark$ \\
& & & \\
Weak instrument Wald test (F-Value) & 33.0 & 24.1 & 28.6 \\
Observations & 267 & 267 & 254 \\
$\mathrm{R}^{2}$ & 0.805 & 0.825 & 0.832 \\
Adjusted $\mathrm{R}^{2}$ & 0.791 & 0.811 & 0.815 \\
\hline \hline
\end{tabular}

Notes: The sample is an unbalanced panel that covers 15 European countries between 1992 and 2010. Germany, France, Italy and the UK are excluded from the sample as members of the G7. The dependent variable in all columns is the domestic environmental policy stringency index. All model specifications include fixed effects for 19 countries and a common linear time trend. Columns (2) and (3) also include a set of control variables. Business cycle, trade and technology controls consist of the national unemployment rate, the logged share of exports plus imports over GDP and the logged patent stock invented by domestic residents. Demographic and sector controls include the following: First, the ratio between the population share of the working age population (16-65 years old) to pensioners $(65+$ years old), then the female labor force participation rate as well as the $\log$ of the national population and the log of total manufacturing employment. Data is from the OECD and Eurostat. Standard errors are clustered at country-level (19 countries) and are robust against heteroskedasticity. Significance levels for the coefficients are indicated as: ${ }^{*} \mathrm{p}<0.1 ;{ }^{* *} \mathrm{p}<0.05 ;{ }^{* *} \mathrm{p}<0.01$ 
Table 16: The Impact of Environmental Policy Stringency on Employment (IV Fixed Effects)

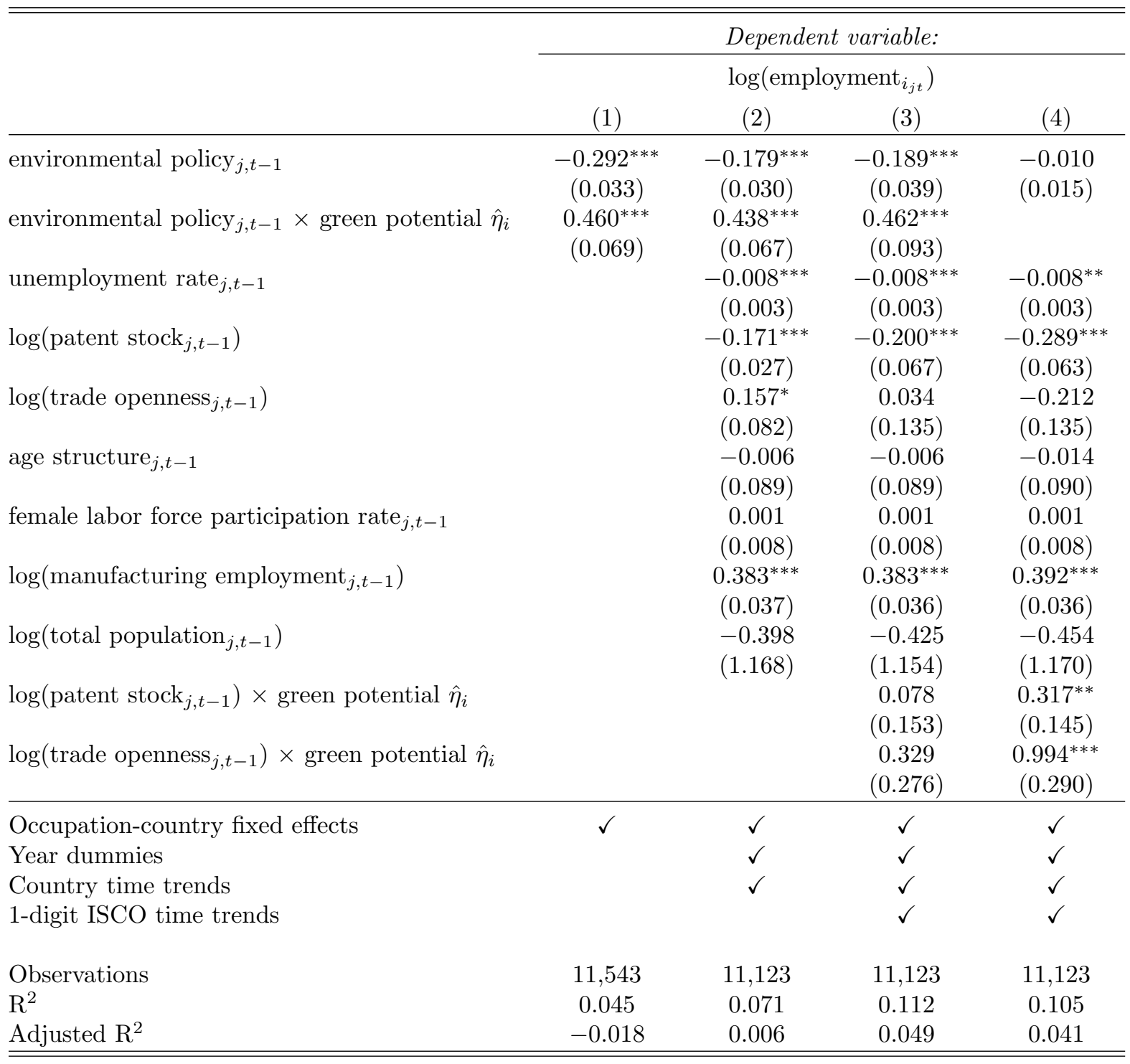

Notes: The sample is an unbalanced panel that covers 19 European countries between 1992 and 2010. The dependent variable in all columns is the log of occupational employment. All model specifications include fixed effects for country-specific occupations. Columns (2) to (4) also include year dummies, country-specific linear time trends and a set of control variables. The controls consist of the national unemployment rate, the logged share of exports plus imports over GDP, the logged patent stock invented by domestic residents, the ratio between the population share of the working age population (16-65 years old) to pensioners $(65+$ years old), the female labor force participation rate as well as the log of total population and the log of total manufacturing employment. In columns (3) and (4) we additionally interact the trade and technology control variables with the green potential measure $\hat{\eta}_{i}$, thereby constructing two new controls on the occupation level. Moreover, columns (3) and (4) also include a linear time trend on the 1-digit ISCO level. Data is from the OECD and Eurostat. Standard errors are clustered at country-specific occupations (721 country-specific ISCO 3-digit occupations) and are robust against heteroskedasticity. Significance levels for the coefficients are indicated as: ${ }^{*} \mathrm{p}<0.1$; ${ }^{* *} \mathrm{p}<0.05 ;{ }^{* * *} \mathrm{p}<0.01$ 
Table 17: Impact of Environmental Policy Stringency on Employment (IV Fixed Effects): G7 member countries excluded

\begin{tabular}{|c|c|c|c|c|}
\hline & \multicolumn{4}{|c|}{ Dependent variable: } \\
\hline & \multicolumn{4}{|c|}{$\log \left(\right.$ employment $\left._{i_{j t}}\right)$} \\
\hline & $(1)$ & $(2)$ & $(3)$ & $(4)$ \\
\hline Environmental Policy $_{j, t-1}$ & $\begin{array}{c}-0.261^{* * *} \\
(0.038)\end{array}$ & $\begin{array}{c}-0.176^{* * *} \\
(0.033)\end{array}$ & $\begin{array}{c}-0.214^{* * *} \\
(0.045)\end{array}$ & $\begin{array}{l}-0.016 \\
(0.018)\end{array}$ \\
\hline $\begin{array}{l}\text { Environmental Policy }{ }_{j, t-1} \times \\
\text { Green Potential } \hat{\eta}_{i}\end{array}$ & $\begin{array}{c}0.422^{* * *} \\
(0.077)\end{array}$ & $\begin{array}{c}0.408^{* * *} \\
(0.074)\end{array}$ & $\begin{array}{c}0.505^{* * *} \\
(0.106)\end{array}$ & \\
\hline Occupation-country fixed effects & $\checkmark$ & $\checkmark$ & $\checkmark$ & $\checkmark$ \\
\hline Year dummies & & $\checkmark$ & $\checkmark$ & $\checkmark$ \\
\hline Country time trends & & $\checkmark$ & $\checkmark$ & $\checkmark$ \\
\hline Business cycle, trade \& technology & & $\checkmark$ & $\checkmark$ & $\checkmark$ \\
\hline Demographic \& sector controls & & $\checkmark$ & $\checkmark$ & $\checkmark$ \\
\hline Trade \& technology interactions & & & $\checkmark$ & $\checkmark$ \\
\hline 1-digit ISCO time trends & & & $\checkmark$ & $\checkmark$ \\
\hline Observations & 9,098 & 8,678 & 8,678 & 8,678 \\
\hline $\mathrm{R}^{2}$ & 0.033 & 0.064 & 0.109 & 0.101 \\
\hline Adjusted $\mathrm{R}^{2}$ & -0.033 & -0.004 & 0.043 & 0.034 \\
\hline
\end{tabular}

Notes: The sample is an unbalanced panel that covers 15 European countries between 1992 and 2010. The G7 member countries France, Germany, Italy and the UK are excluded from the sample. The dependent variable in all columns is the log of occupational employment. All model specifications include fixed effects for country-specific occupations. Columns (2) to (4) further include year dummies, countryspecific linear time trends and a set of control variables. More specifically, columns (2) to (4) include the national unemployment rate, the logged share of exports plus imports over GDP and the logged patent stock invented by domestic residents to control for the business cycle as well as trends in trade and technology. Demographic and sector controls consist of the following variables: The working age (16-64 years old) to pension age (65 years and older) ratio, the female labor force participation rate, the $\log$ of the total population and the log of total manufacturing employment. In columns (3) and (4) the trade and technology control variables from column (2) are additionally interacted with the green potential measure $\hat{\eta}_{i}$, thereby constructing two new controls on the occupation level. Moreover, columns (3) and (4) incorporate a linear time trend on the 1-digit ISCO level. Data is from the OECD and Eurostat. Standard errors in parentheses are clustered at the level of country-specific occupations (550 country-specific ISCO 3-digit occupations) and are robust against heteroskedasticity. Significance levels for the coefficients are indicated as: ${ }^{*} \mathrm{p}<0.1 ;{ }^{* *} \mathrm{p}<0.05 ;{ }^{* * *} \mathrm{p}<0.01$ 
Table 18: Impact of environmental policy stringency on employment (IV Fixed Effects)

\begin{tabular}{|c|c|c|c|}
\hline & \multicolumn{3}{|c|}{ Dependent variable: } \\
\hline & \multicolumn{3}{|c|}{$\log \left(\right.$ employment $\left._{i_{j t}}\right)$} \\
\hline & $(1)$ & $(2)$ & $(3)$ \\
\hline 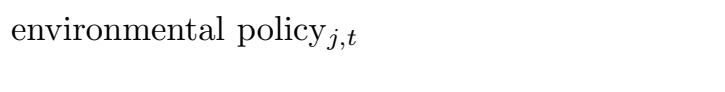 & $\begin{array}{c}-0.157^{* * *} \\
(0.037)\end{array}$ & & \\
\hline 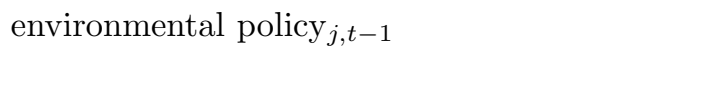 & & $\begin{array}{c}-0.189^{* * *} \\
(0.039)\end{array}$ & \\
\hline environmental policy $j_{j, t-2}$ & & & $\begin{array}{c}-0.155^{* * *} \\
(0.041)\end{array}$ \\
\hline environmental policy ${ }_{j, t} \times$ green potential $\hat{\eta}_{i}$ & $\begin{array}{c}0.436^{* * *} \\
(0.091)\end{array}$ & & \\
\hline environmental policy $j_{j, t-1} \times$ green potential $\hat{\eta}_{i}$ & & $\begin{array}{c}0.462^{* * *} \\
(0.093)\end{array}$ & \\
\hline environmental policy $_{j, t-2} \times$ green potential $\hat{\eta}_{i}$ & & & $\begin{array}{c}0.523^{* * *} \\
(0.099)\end{array}$ \\
\hline Occupation-country fixed effects & $\checkmark$ & $\checkmark$ & $\checkmark$ \\
\hline Year dummies & $\checkmark$ & $\checkmark$ & $\checkmark$ \\
\hline Country time trends & $\checkmark$ & $\checkmark$ & $\checkmark$ \\
\hline Business cycle, trade \& technology & $\checkmark$ & $\checkmark$ & $\checkmark$ \\
\hline Demographic controls & $\checkmark$ & $\checkmark$ & $\checkmark$ \\
\hline Trade \& technology interactions & $\checkmark$ & $\checkmark$ & $\checkmark$ \\
\hline 1-digit ISCO time trends & $\checkmark$ & $\checkmark$ & $\checkmark$ \\
\hline Observations & 11,807 & 11,123 & 10,438 \\
\hline $\mathrm{R}^{2}$ & 0.166 & 0.112 & 0.095 \\
\hline Adjusted $\mathrm{R}^{2}$ & 0.110 & 0.049 & 0.026 \\
\hline
\end{tabular}

Notes: The sample is an unbalanced panel that covers 19 European countries between 1992 and 2010. The dependent variable in all columns is the log of occupational employment. The regression model in all columns includes fixed effects for country-specific occupations, year dummies, country-specific linear time trends and a set of control variables. More specifically, the national unemployment rate, the logged share of exports plus imports over GDP and the logged patent stock invented by domestic residents control for the business cycle as well as trends in trade and technology. Demographic and sector controls consist of the following variables: The working age (16-64 years old) to pension age (65 years and older) ratio, the female labor force participation rate, the log of the total population and the log of total manufacturing employment. Moreover, the trade and technology control variables are additionally interacted with the green potential measure $\hat{\eta}_{i}$, which provides two additional control variables on the occupation level. Lastly, the model incorporates a linear time trend on the 1-digit ISCO level. Data is from the OECD and Eurostat. Standard errors in parentheses are clustered at the level of country-specific occupations and are robust against heteroskedasticity. Significance levels for the coefficients are indicated as: ${ }^{*} \mathrm{p}<0.1 ;{ }^{* *} \mathrm{p}<0.05$; *** $\mathrm{p}<0.01$ 
Table 19: Placebo Regression (Fixed Effects and IV Fixed Effects Estimations)

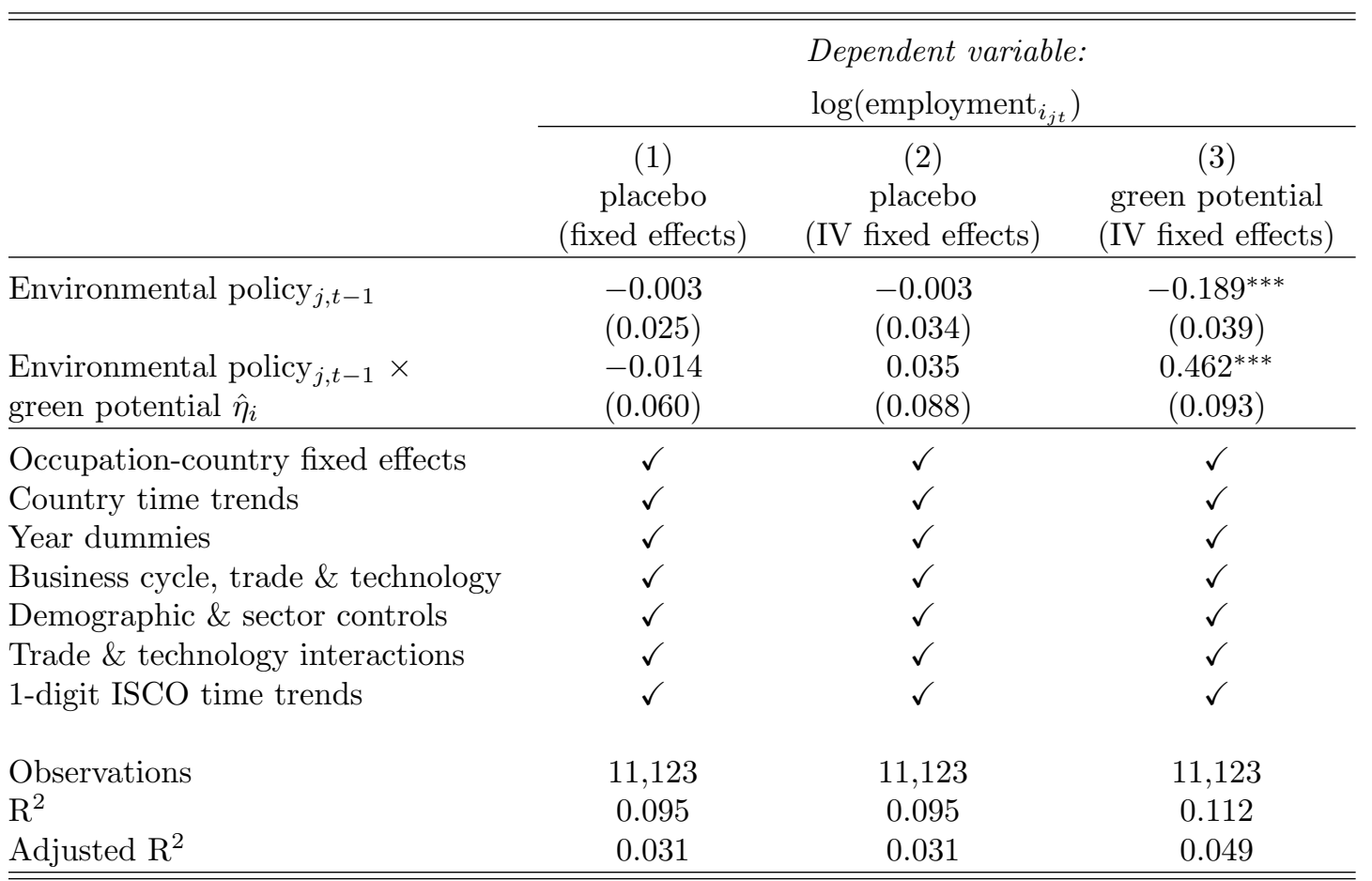

Notes: The sample is an unbalanced panel that covers 19 European countries between 1992 and 2010. The dependent variable in all columns is the log of occupational employment. The regression model in all columns includes fixed effects for country-specific occupations, year dummies, country-specific linear time trends and a set of control variables. More specifically, the national unemployment rate, the logged share of exports plus imports over GDP and the logged patent stock invented by domestic residents control for the business cycle as well as trends in trade and technology. Demographic and sector controls consist of the following variables: The working age (16-64 years old) to pension age (65 years and older) ratio, the female labor force participation rate, the $\log$ of the total population and the log of total manufacturing employment. Moreover, the trade and technology control variables are additionally interacted with the green potential measure $\hat{\eta}_{i}$, which provides two additional control variables on the occupation level. Lastly, the model incorporates a linear time trend on the 1-digit ISCO level. Data is from the OECD and Eurostat. Standard errors in parentheses are clustered at the level of country-specific occupations and are robust against heteroskedasticity. Significance levels for the coefficients are indicated as: ${ }^{*} \mathrm{p}<0.1 ;{ }^{* *} \mathrm{p}<0.05 ;{ }^{* * *} \mathrm{p}<0.01$ 
Table 20: Impact of Environmental Policy Stringency on Employment (IV Fixed Effects): Routine-Task Intensity and Offshorability

\begin{tabular}{|c|c|c|c|c|}
\hline & \multicolumn{4}{|c|}{ Dependent variable: } \\
\hline & \multicolumn{4}{|c|}{$\log \left(\right.$ employment $\left._{i_{j t}}\right)$} \\
\hline & $(1)$ & $(2)$ & $(3)$ & $(4)$ \\
\hline & RTI & BK & RTI \& BK & baseline \\
\hline Environmental Policy $_{j, t-1}$ & $\begin{array}{c}-0.129^{*} \\
(0.056)\end{array}$ & $\begin{array}{c}-0.156^{* * *} \\
(0.044)\end{array}$ & $\begin{array}{c}-0.126^{*} \\
(0.061)\end{array}$ & $\begin{array}{c}-0.189^{* * *} \\
(0.039)\end{array}$ \\
\hline $\begin{array}{l}\text { Environmental Policy }{ }_{j, t-1} \times \\
\text { Green Potential } \hat{\eta}_{i}\end{array}$ & $\begin{array}{c}0.507^{* * *} \\
(0.087)\end{array}$ & $\begin{array}{c}0.515^{* * *} \\
(0.087) \\
\end{array}$ & $\begin{array}{c}0.431^{* * *} \\
(0.091)\end{array}$ & $\begin{array}{c}0.462^{* * *} \\
(0.093)\end{array}$ \\
\hline Occupation-country fixed effects & $\checkmark$ & $\checkmark$ & $\checkmark$ & $\checkmark$ \\
\hline Year dummies & $\checkmark$ & $\checkmark$ & $\checkmark$ & $\checkmark$ \\
\hline Country time trends & $\checkmark$ & $\checkmark$ & $\checkmark$ & $\checkmark$ \\
\hline Business cycle, trade \& technology & $\checkmark$ & $\checkmark$ & $\checkmark$ & $\checkmark$ \\
\hline Demographic \& sector controls & $\checkmark$ & $\checkmark$ & $\checkmark$ & $\checkmark$ \\
\hline \multicolumn{5}{|l|}{ ISCO-level controls } \\
\hline 1-digit ISCO time trends & $\checkmark$ & $\checkmark$ & $\checkmark$ & $\checkmark$ \\
\hline Trade \& technology interactions & & & & $\checkmark$ \\
\hline Environmental Policy $_{j, t-1} \times$ Routine-Task Intensity & $\checkmark$ & & $\checkmark$ & \\
\hline Environmental Policy $_{j, t-1} \times$ Offshorability & & $\checkmark$ & $\checkmark$ & \\
\hline Observations & 11,087 & 11,087 & 11,1087 & 11,123 \\
\hline $\mathrm{R}^{2}$ & 0.108 & 0.108 & 0.110 & 0.112 \\
\hline Adjusted $\mathrm{R}^{2}$ & 0.045 & 0.045 & 0.041 & 0.047 \\
\hline
\end{tabular}

Notes: The sample is an unbalanced panel that covers 19 European countries between 1992 and 2010. The dependent variable in all columns is the log of occupational employment. All model specifications include fixed effects for country-specific occupations, year dummies, country-specific linear time trends and a set of control variables. More specifically, they include the national unemployment rate, the logged share of exports plus imports over GDP and the logged patent stock invented by domestic residents to control for the business cycle as well as trends in trade and technology. Demographic and sector controls consist of the following variables: The working age (16-64 years old) to pension age (65 years and older) ratio, the female labor force participation rate, the log of the total population and the log of total manufacturing employment. Moreover, all specifications incorporate a linear time trend on the 1-digit ISCO level. Routine-task intensity from Goos et al. (2014) and the offshorability from Blinder and Krueger (2013) are measured at the ISCO 2-digit level, thereby constructing two new controls on the occupation level. The baseline regression specification featuring interactions of the green potential measure $\hat{\eta}_{i}$ with the trade and technology control variables from columns (1) to (3) is shown in column (4). Data is from the OECD and Eurostat. Standard errors in parentheses are clustered at the level of country-specific occupations (721 country-specific ISCO 3-digit occupations) and are robust against heteroskedasticity. Significance levels for the coefficients are indicated as: ${ }^{*} \mathrm{p}<0.1 ;{ }^{* *} \mathrm{p}<0.05 ;{ }^{* * *} \mathrm{p}<0.01$ 
Table 21: Impact of Environmental Policy Stringency on Employment (IV Fixed Effects): Period Averages

\begin{tabular}{lccc}
\hline \hline & \multicolumn{3}{c}{ Dependent variable: } \\
\cline { 2 - 4 } & & $\log \left(\right.$ employment $\left._{i_{j}}\right)$ & \\
& 3-year averages & 4-year averages & baseline \\
\hline Environmental Policy $j, t-1$ & $-0.182^{* * *}$ & $-0.265^{* *}$ & $-0.189^{* * *}$ \\
& $(0.051)$ & $(0.087)$ & $(0.039)$ \\
Environmental Policy $j, t-1$ & $0.548^{* * *}$ & $0.689^{* * *}$ & $0.462^{* * *}$ \\
Green Potential $\hat{\eta}_{i}$ & $(0.101)$ & $(0.118)$ & $(0.093)$ \\
\hline Occupation-country fixed effects & $\checkmark$ & $\checkmark$ & $\checkmark$ \\
Year dummies & $\checkmark$ & $\checkmark$ & $\checkmark$ \\
Country time trends & $\checkmark$ & $\checkmark$ & $\checkmark$ \\
Business cycle, trade \& technology & $\checkmark$ & $\checkmark$ & $\checkmark$ \\
Demographic \& sector controls & $\checkmark$ & $\checkmark$ & $\checkmark$ \\
Trade \& technology interactions & $\checkmark$ & $\checkmark$ & $\checkmark$ \\
1-digit ISCO time trends & $\checkmark$ & $\checkmark$ & $\checkmark$ \\
& & & \\
Observations & 3,139 & 2,469 & 11,123 \\
$\mathrm{R}^{2}$ & 0.118 & 0.143 & 0.112 \\
Adjusted R ${ }^{2}$ & -0.212 & -0.193 & 0.049 \\
\hline \hline
\end{tabular}

Notes: The sample is an unbalanced panel that covers 19 European countries between 1992 and 2010. The dependent variable in all columns is the log of occupational employment. The regression model in all columns includes fixed effects for country-specific occupations, year dummies, country-specific linear time trends and a set of control variables. More specifically, the national unemployment rate, the logged share of exports plus imports over GDP and the logged patent stock invented by domestic residents control for the business cycle as well as trends in trade and technology. Demographic and sector controls consist of the following variables: The working age (16-64 years old) to pension age (65 years and older) ratio, the female labor force participation rate, the log of the total population and the log of total manufacturing employment. Moreover, the trade and technology control variables are additionally interacted with the green potential measure $\hat{\eta}_{i}$, which provides two additional control variables on the occupation level. Lastly, the model incorporates a linear time trend on the 1-digit ISCO level. Data is from the OECD and Eurostat. Standard errors in parentheses are clustered at the level of country-specific occupations and are robust against heteroskedasticity. Significance levels for the coefficients are indicated as: ${ }^{*} \mathrm{p}<0.1$; ${ }^{* *} \mathrm{p}<0.05 ;{ }^{* * *} \mathrm{p}<0.01$ 
Table 22: Impact of Environmental Policy Stringency on Employment (IV Fixed Effects): EPS SubIndicators

\begin{tabular}{lccccc}
\hline \hline & \multicolumn{5}{c}{ Dependent variable: } \\
\cline { 2 - 6 } & \multicolumn{5}{c}{$\log \left(\right.$ employment $\left._{i_{j}}\right)$} \\
& $(1)$ & $(2)$ & $(3)$ & $(4)$ & $(5)$ \\
& market & non-market & taxes & trading & standards \\
& measures & measures & & schemes \\
\hline Environmental Policy ${ }_{j, t-1}$ & $-0.236^{* * *}$ & $-0.123^{* * *}$ & $-0.235^{* *}$ & -0.026 & $-0.058^{* *}$ \\
& $(0.042)$ & $(0.032)$ & $(0.084)$ & $(0.019)$ & $(0.019)$ \\
Environmental Policy ${ }_{j, t-1} \times$ & $0.528^{* * *}$ & $0.377^{* * *}$ & $0.550^{* *}$ & $0.159^{* * *}$ & $0.220^{* * *}$ \\
Green Potential $\hat{\eta}_{i}$ & $(0.106)$ & $(0.078)$ & $(0.203)$ & $(0.033)$ & $(0.046)$ \\
\hline Occupation-country fixed effects & $\checkmark$ & $\checkmark$ & $\checkmark$ & $\checkmark$ & $\checkmark$ \\
Year dummies & $\checkmark$ & $\checkmark$ & $\checkmark$ & $\checkmark$ & $\checkmark$ \\
Country time trends & $\checkmark$ & $\checkmark$ & $\checkmark$ & $\checkmark$ & $\checkmark$ \\
Business cycle, trade \& technology & $\checkmark$ & $\checkmark$ & $\checkmark$ & $\checkmark$ & $\checkmark$ \\
Demographic \& sector controls & $\checkmark$ & $\checkmark$ & $\checkmark$ & $\checkmark$ & $\checkmark$ \\
Trade \& technology interactions & $\checkmark$ & $\checkmark$ & $\checkmark$ & $\checkmark$ & $\checkmark$ \\
1-digit ISCO time trends & $\checkmark$ & $\checkmark$ & $\checkmark$ & $\checkmark$ & $\checkmark$ \\
& & & & \\
Observations & 11,123 & 11,123 & 11,123 & 11,123 & 11,123 \\
$\mathrm{R}^{2}$ & 0.105 & 0.108 & 0.099 & 0.108 & 0.109 \\
Adjusted R ${ }^{2}$ & 0.042 & 0.045 & 0.035 & 0.045 & 0.045 \\
\hline \hline
\end{tabular}

Notes: The sample is an unbalanced panel that covers 19 European countries between 1992 and 2010. The dependent variable in all columns is the log of occupational employment. The regression model in all columns includes fixed effects for country-specific occupations, year dummies, country-specific linear time trends and a set of control variables. More specifically, the national unemployment rate, the logged share of exports plus imports over GDP and the logged patent stock invented by domestic residents control for the business cycle as well as trends in trade and technology. Demographic and sector controls consist of the following variables: The working age (16-64 years old) to pension age (65 years and older) ratio, the female labor force participation rate, the log of the total population and the log of total manufacturing employment. Moreover, the trade and technology control variables are additionally interacted with the green potential measure $\hat{\eta}_{i}$, which provides two additional control variables on the occupation level. Lastly, the model incorporates a linear time trend on the 1-digit ISCO level. Data is from the OECD and Eurostat. Standard errors in parentheses are clustered at the level of country-specific occupations and are robust against heteroskedasticity. Significance levels for the coefficients are indicated as: ${ }^{*} \mathrm{p}<0.1 ;{ }^{* *} \mathrm{p}<0.05 ;{ }^{* * *} \mathrm{p}<0.01$ 